\title{
A nonlinear shear-lag model applied to chemical anchors subjected to a temperature distribution
}

Mohamed Amine Lahouar ${ }^{\mathrm{a}, \mathrm{b}, *}$, Nicolas Pinoteau $^{\mathrm{b}}$, Jean-François Caron $^{\mathrm{a}}$, Gilles Foret ${ }^{\mathrm{a}}$, Romain Mege ${ }^{b}$

${ }^{a}$ Université Paris-Est, Laboratoire Navier (UMR 8205), Ecole des Ponts ParisTech, F-77455 Marnela-Vallée, France

${ }^{\mathrm{b}}$ Université Paris-Est, Centre Scientifique et Technique du Bâtiment (CSTB), 84 avenue Jean Jaurès, Champs-sur-Marne, 77447 Marne-la-Vallée Cedex 2, FRANCE.

*Corresponding author. Tel: +33630242016. E-mail address: amine.lahouar@enpc.fr. Present address: 6-8 Avenue Blaise Pascal, Ecole Nationale des Ponts et Chaussées, 77420 Champs-surMarne, France.

\begin{abstract}
Adhesive joints are increasingly used in bridges and buildings construction thanks to their high mechanical properties and their ease of implementation. However, the load transfer mechanism within adhesive joints is complex and has been the subject of several studies since 1938. Several models have been developed to quantify the stress distribution along bond joints. Nevertheless, very few models exist today to study the stress distribution in chemical anchors by taking into account the temperature effect. This paper presents a non-linear shear-lag model adapted to chemical anchors allowing predicting their stress distribution profiles and fire resistance duration for any temperature distribution. The model highlights the importance of the temperature distribution on the stress profile. The paper shows that when the anchor reaches its maximum axial force, all the elements composing the anchor provide their maximum performance at the same time.
\end{abstract}

\section{Introduction}

Over the years, the use of structural adhesive bonding techniques in concrete constructions is constantly increasing [1]. Bonding techniques are employed for different applications such as cracks and joints filling, bonding concrete to concrete, metal to metal, steel to concrete and recently composite materials to timber or concrete [2] [3]. The main advantage of the use of bonding techniques in construction is that bond stresses are more uniformly distributed over the bonded surface area than with other conventional fastening methods such as bolts and rivets [4]. This allows working with small bearing areas, and therefore leads to lighten the weight of the structure.

Adhesive joints ensure the load transfer from one adherent to another, essentially by shear stress. Nevertheless, the stress distribution along the bond joint is not usually uniform, and exhibit localized concentration in specific areas, which reduces the bond resistance and leads in the majority of cases to its failure [5]. Several studies have been conducted and refined for more than seven decades in order to analyze the axial, shear and peel stress distribution along the bond joint. Volkersen [6] was the first to propose a simple Shear-lag model in 1938, to predict the stress distribution along a mechanical joint with several fasteners. Later, the model was adapted for bonded lap joints but still ignoring the bending and the shear deformation of the adherents, in addition to ignoring the peel stress at the free ends of the joint. In 1944, Goland and Reissner [7] improved the Volkersen model by considering the shear and normal transverse deformations of the bond. After that, the shear-lag model was enhanced by Oplinger [8] by introducing a layered beam theory instead of the classical homogeneous beam model for single lap joints. The improvements made on the Volkersen model were continued with Hart-Smith [9] by including elastic-plastic adhesive behavior, and then by Tsai, Oplinger and Morton [10] by assuming a linear bond stress distribution along the adherents. 
Since the 1970s, several numerical models have been developed to analyze the stress distribution in adhesively bonded joint. The development of sophisticated numerical tools has widened the scope of study by including new points of interest. Numerous studies have focused on the mechanical analysis of lap joints by predicting the stress concentration factors [11], implementing new theories [12] and nonlinear constitutive laws [13], testing different extension rates [14] and by evaluating the influence of the material properties on the stress distribution [15].

Numerical calculation tools were also used to predict the adhesive joint failure by analyzing the interfacial debonding mechanism using two different approaches:

- The strength of materials approach, which depends on the material properties and supposes that debonding occurs when the stress or the material strain exceeds a threshold value [16].

- The fracture mechanics approach, which involves the generalized stress intensity factors and the crack initiation factor. In this approach, the crack propagates once the interfacial toughness is exceeded [17].

The analysis of the debonding mechanism using these two approaches allowed concluding that the debonding starts always from the free ends, i.e. from the stress concentration areas. Consequently, several numerical and experimental parametric studies have been conducted to improve the strength properties of adhesively bonded joints. These studies target to reduce the amplitude of the stress peaks at the ends of the joint, making the stress more uniformly distributed over the bond.

Numerous researchers have studied the influence of the adhesive thickness on the mechanical performance of adhesively bonded joints and showed that the maximum strength decreases by increasing the adhesive thickness [18]. Other studies showed that when the thickness of the bond is not constant, the stresses are concentrated in the smallest thickness [19]. It has also been demonstrated that increasing the bond length decreases the amplitude of the shear peak and makes the bond stress more uniformly distributed [4] [20].

Other studies showed that the mechanical performance of an adhesive joint could be improved by properly varying the mechanical properties of the adhesive over the bond length. Indeed, the variation of the adhesive shear modulus over the bond leads to reduce the stress concentration at the ends of the joint [5]. The use of several adhesives in the same bond joint is one of the widely used techniques to improve the bond stiffness and shear modulus. Stiff and strong adhesives are used in the middle of the joint, and flexible and ductile adhesives are positioned at the ends [21]. This configuration leads to a more uniform stress distribution and increases the bond strength [22] [23].

In conclusion, parametric studies carried out on adhesively bonded joints have shown that the mechanical performance of the bond joint is mainly governed by the bond geometry and by the material properties of the adherents and adhesive. Almost all research works cited here were interested in the study of the stress distribution along the adhesively bonded joints without taking into account the temperature effect. Nevertheless, Carbas et al. [24] showed that temperature modifies considerably the mechanical properties of the adhesive joint.

This paper presents a nonlinear shear-lag model adapted to chemical anchors by taking into account the influence of temperature. The objective of this paper is to study the temperature effect on the stress distribution along the anchor and on its mechanical behavior, as well as on its fire resistance duration.

The first part of this paper is devoted to the adaptation of the shear-lag model to the mechanical problem of chemical anchors and to the thermo-mechanical coupling, while exposing the assumptions and the steps followed to constitute the model. The second part is reserved to study the effect of a uniform temperature distribution on the stress profile along the anchor. This part is also devoted to the analytical and numerical resolution of the shear-lag differential equation and to the adaptation of the model to the imposed displacement mode for practical reasons. The third part of the paper deals with the general case 
of temperature distribution for anchors in structure under fire situation. This part focuses on the evolution of the mechanical behavior of the anchor for a given thermal profile and for different loading levels. Finally, the last part of the paper is devoted to the model validation by comparing the shear-lag model results with the experimental data and with results obtained by the resistance integration method, used to predict the fire resistance of chemical anchors.

Despite the fact that the model developed in this paper makes it possible to establish robust conclusions on the influence of temperature variation on the mechanical behavior of chemical anchors, it shows some limitations that require reflection and development. These limits are mainly related to the nonconsideration of the ribs of the steel rebar, of the possible imperfections that may occur during the implementation of the chemical anchor, of the thermal expansion of steel and concrete, and of the viscoelastic behavior of the resin.

\section{Nomenclature}

$\sigma^{s}:$ Axial stress in the steel rebar section [MPa]

$\sigma^{c}:$ Axial stress in the concrete section [MPa]

$\varepsilon^{s}:$ Steel rebar axial strain

$\varepsilon^{c}:$ Concrete axial strain

$E^{s}$ : Steel rebar elastic modulus (independent of temperature) [MPa]

$E^{c}$ : Concrete elastic modulus (temperature dependent) [MPa]

$A^{S}:$ Steel rebar section $\left[\mathrm{mm}^{2}\right]$

$\underline{A^{c}: \text { Concrete section }\left[\mathrm{mm}^{2}\right]}$

$\underline{R}:$ Steel rebar radius $[\mathrm{mm}]$

$L$ : Embedment length [mm]

$\tau$ : Adhesive bond stress [MPa]

$\mathrm{U}^{\mathrm{S}}(\mathrm{x})$ : Elastic axial displacement of the steel rebar [mm]

$\mathrm{U}^{c}(\mathrm{x})$ : Elastic axial displacement of the concrete induced by concrete crushing [mm]

$\mathrm{V}$ : Axial displacement induced by the shearing of the adhesive at the bottom of the anchor [mm]

$\delta:$ Rebar slip [mm]

$\theta:$ Temperature of the element of anchor $\left[{ }^{\circ} \mathrm{C}\right]$

\section{Shear-lag model adapted to the mechanical problem of chemical anchors}

Almost all shear-lag models presented in the literature analyze the stresses distribution along flat single or double lap joints at cold state. However, very few models take into account the temperature effect. This section deals with the adaptation of the shear-lag equations to the mechanical problem of chemically bounded anchors under temperature exposure. The studied configuration is composed of a concrete cylinder drilled axially in its center, and of a steel rebar of radius $R$, introduced into the drilled hole along an embedment length $L$. The spacing between the steel rebar and concrete, representing the thickness of the adhesive joint, denoted $e$ (Fig. 1), is assumed to be negligible. The adhesion between steel and concrete is assumed to be perfect. An axial tensile force $F$ is applied to the rebar, at the beginning of the anchor. The axial stress is assumed to be equal to zero at the bottom of the anchor. The anchor is attached to a cylindrical coordinate system, where the anchor axis corresponds to the $\mathrm{x}$-axis and the abscissa zero corresponds to the bottom of the anchor. Fig. 1 represents the geometry and the mechanical configuration of the studied chemical anchor. 


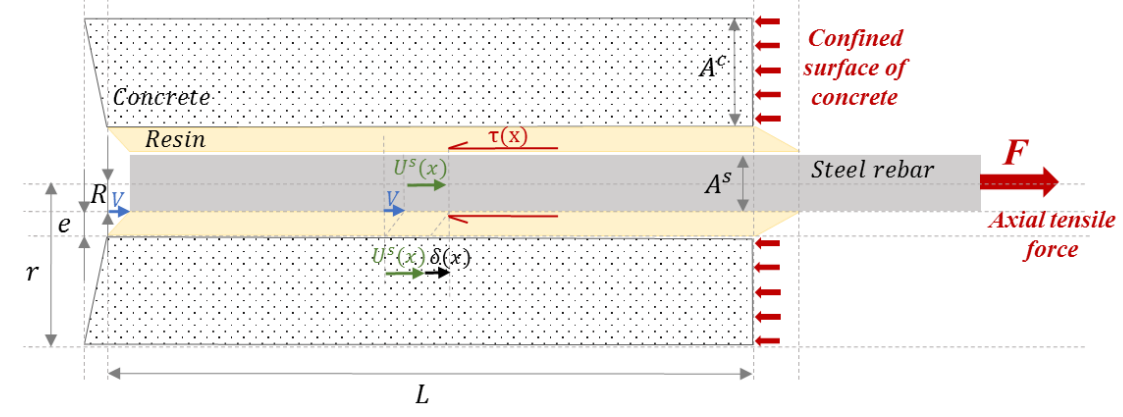

Fig. 1: Geometrical and mechanical configuration of the studied anchor

\section{1- Model assumptions and notions}

Five assumptions are made in order to simplify the shear-lag resolution.

i. The adherents (rebar and concrete) are homogeneous and linear elastic.

ii. The adhesive transfers the axial load from the rebar to concrete only by shear stress.

iii. Bending effects are neglected.

iv. The normal stresses are uniformly distributed over the cross sections of the rebar and concrete.

v. The thickness and width of the adhesive and the adherents are constant throughout the bond line.

vi. Radial deformations of the steel rebar are neglected

vii. The temperature is supposed constant in a bond ring of length $\mathrm{dx}$. This ring includes concrete, mortar, steel and the two interfaces.

\section{2- Constitutive equations}

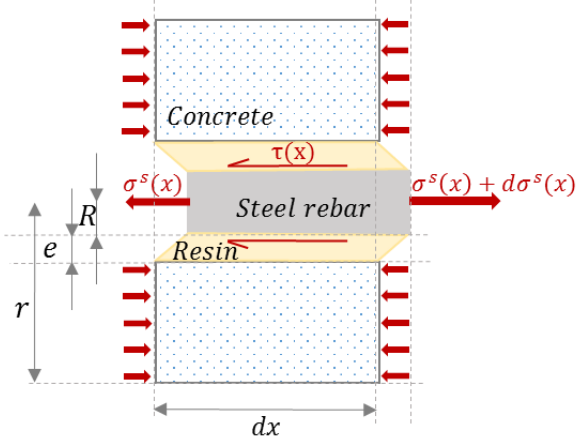

Fig. 2: Forces equilibrium in the section of an element of the anchor

Let us consider the element of the anchor presented in Fig. 2. The equation of the forces equilibrium can be written as follows.

$\sigma^{s}(x) A^{s}+\sigma^{c}(x) A^{c}=0$

In this equation, the axial stress is assumed to be independent of the radial coordinate of the anchor element (assumptions iv and vi). These assumptions are generally accepted and used for steel. However, it remains to be checked in the radial direction of the concrete section $A^{c}$. This verification is necessary since the concrete section $A^{c}$ will be used further in the shear-lag calculations.

The relationship between the axial stress and the adhesive bond stress is obtained by load equilibrium on an element of the bond of length $d x$ (equation (2)).

$\tau(x)=\frac{R}{2} \frac{d \sigma^{s}(x)}{d x}$ 
The anchor slip $\delta(x)$ is defined as the difference between the rebar mean displacement and the concrete mean displacement at a position $\mathrm{x}$. The rebar displacement is composed of two displacements. A displacement denoted $\mathrm{U}^{S}(\mathrm{x})$ induced by the elastic elongation of the steel (which depends on $\mathrm{x}$ ), and a displacement $\mathrm{V}$ corresponding to the displacement of the rebar at the bottom of the anchor induced by the shearing of the bond joint (independent of $x$ ). The concrete displacement, denoted $U^{c}(x)$, is induced by the concrete compression and depends on the position $\mathrm{x}$ of the anchor element.

$\delta(x)=U^{s}(x)+V-U^{c}(x)$

According to assumption i, steel and concrete are considered as elastic materials. The axial strain in these two materials are assumed to be uniform in the section, according to assumption iv. Then, Hooke's law can be applied to express the axial strain as a function of axial stress and Young's moduli of steel and concrete (equation (4)). Since the studied temperatures do not exceed $200^{\circ} \mathrm{C}$, it is assumed that the steel elastic modulus is independent of temperature while the concrete elastic modulus varies with temperature, according to Eurocode 2 part 1-2 [25].

$\frac{d \delta(x)}{d x}=\frac{d U^{s}(x)}{d x}-\frac{d U^{c}(x)}{d x}=\varepsilon^{s}(x)-\varepsilon^{c}(x)=\frac{\sigma^{s}(x)}{E^{s}}-\frac{\sigma^{c}(x)}{E^{c}(\theta(x))}$

Equation (5) is obtained by substituting equation (1) into equation (4), allowing to link the rebar slip to the axial stress.

$\frac{d \delta(x)}{d x}=\sigma^{S}(x)\left(\frac{1}{E^{S}}+\frac{A^{S}}{A^{c}} \cdot \frac{1}{E^{c}(\theta(x))}\right)$

Using equations (2) and (5), it is possible to establish the constitutive equation of the shear-lag model (equation (6)) allowing describing the slip evolution of the anchor elements.

$\frac{d^{2} \delta(x)}{d x^{2}}=\frac{2}{R}\left(\frac{1}{E^{S}}+\frac{A^{S}}{A^{c}} \cdot \frac{1}{E^{c}(\theta(x))}\right) \tau(x)$

In order to solve the shear-lag equation, it is necessary to transform it into a second order differential equation. Therefore, it is essential to establish a relationship between the bond stress and the anchor slip, as described in equation (7).

$\tau(x)=f(\delta(x), \theta(x))$

This relationship can be derived either from the characterization of the mechanical behavior of the adhesive at different temperatures, and in this case, the local mechanical properties of the resin $\left(G_{\text {resin }}\right)$ will be taken into account in the equation resolution, or from the characterization of the global mechanical behavior of the anchor at different temperatures, and therefore, the mechanical behavior of the resin will be modeled as an interfacial cohesive behavior. In the following study, this relationship will be established by means of pull-out tests, and therefore by the characterization of the global mechanical behavior of the anchor.

Equation (8) represents the differential equation of the shear-lag adapted to the mechanical problem of chemical anchors, taking into account the temperature distribution profile. The resolution of this equation enables the knowledge of the slip profile along the anchor $(\delta(x))$ at different temperatures. It is then possible to deduce the bond stress distribution using the relationship established between anchor slip and the bond stress (equation (7)). Subsequently, the axial stress distribution can be calculated using equation (2).

$\frac{d^{2} \delta(x)}{d x^{2}}=\frac{2}{R}\left(\frac{1}{E^{s}}+\frac{A^{s}}{A^{c} E^{c}(\theta(x))}\right) f(\delta(x), \theta(x))$ 


\section{3- Bond stress-anchor slip relationship}

In this study, the mechanical behavior of the resin will be described as an interfacial behavior in pure shear mode and therefore using a cohesive model. Several cohesive models exist in the literature to describe the bond stress-anchor slip relationship. The simplest models are perfect rigid-plastic and linear models. In the perfect rigid-plastic model, the bond stress is assumed constant and independent of the anchor slip value. Therefore, the model generates a uniform bond stress distribution and leads consequently to a linear distribution of the axial stress. However, in the linear model, the bond stress is assumed to increase linearly by increasing the anchor slip. Note that these two simple cohesive models do not allow to predict the damage of the bond joint. Nevertheless, several models exist in the literature taking into account the damage of the bond joint such as bilinear, exponential and parabolic cohesive models.

In the bilinear model, the bond stress increases linearly by increasing the anchor slip until reaching a threshold value from which the interfacial fracture occurs and the bond stress decreases progressively until zero value, indicating the total damage of the bond joint. While in the exponential cohesive model, the interfacial behavior presents an exponential softening and the stress decreases by increasing the anchor slip. However, in the parabolic cohesive model, the variation of the bond stress as a function of the anchor slip is described by a parabola on which the bond stress increases by increasing the slip until reaching a maximum value and then gradually decreases until reaching zero bond stress. Note that the injection of the rigid-plastic perfect, linear, bilinear and exponential cohesive models allow the analytical resolution of the shear-lag differential equation, however the use of the parabolic cohesive model requires a numerical resolution tool.

\section{Case of a uniform temperature distribution}

This section focuses in the study of the mechanical behavior of chemical anchors in the particular case of a uniform temperature distribution $(\bar{\theta})$. A similar study was conducted Pinoteau [26], using the evolution of the resin mechanical properties with temperature $(\operatorname{Gres}(\theta))$ as input data. However, a study carried out on bonded connections showed that "the stiffness of the bond evolves little as a function of the stiffness of the adhesive when the adhesive stiffness is greater than 200 MPa" [27]. This means that injecting the mechanical properties of the resin into the shear-lag equations does not adequately describe the mechanical behavior of the anchor and leads to an underestimation of the stress profile. This observation was verified in a previous paper [28] by comparing the adhesive stiffness obtained by DMTA characterization tests with the anchors stiffness measured during pull-out tests. In addition, the loading / unloading tests presented in [28] highlighted the damage of the adhesive bond during the pullout tests. Hence, it is more appropriate to use a cohesive law allowing to take into account the bond damage when studying the influence of temperature on the anchor mechanical behavior in order to detect any eventual damage which may occur during the temperature increase.

Therefore, in this section, the bilinear model is chosen as a cohesive model to describe the bond stressanchor slip relationship. The interface between steel and concrete is assumed initially intact without any defects or damage. The bilinear model is described by the equation (9) and represented in Fig. 3. This law allows indeed the analytical resolution of the shear-lag differential equation (8) and the prediction of the bond joint damage.

$$
\tau(\delta(x), \theta(x))=\left\{\begin{array}{c}
\frac{\tau_{f}(\theta)}{\delta_{1}(\theta)} \delta(\theta(x)) \text { when } 0 \leq \delta(\theta(x))<\delta_{1}(\theta) \\
\frac{\tau_{f}(\theta)}{\left(\delta_{f}(\theta)-\delta_{1}(\theta)\right)}\left(\delta_{f}(\theta)-\delta(\theta(x))\right) \text { when } \delta_{1}(\theta) \leq \delta(\theta(x))<\delta_{f}(\theta) \\
0 \text { when } \delta(\theta(x))>\delta_{f}(\theta)
\end{array}\right.
$$




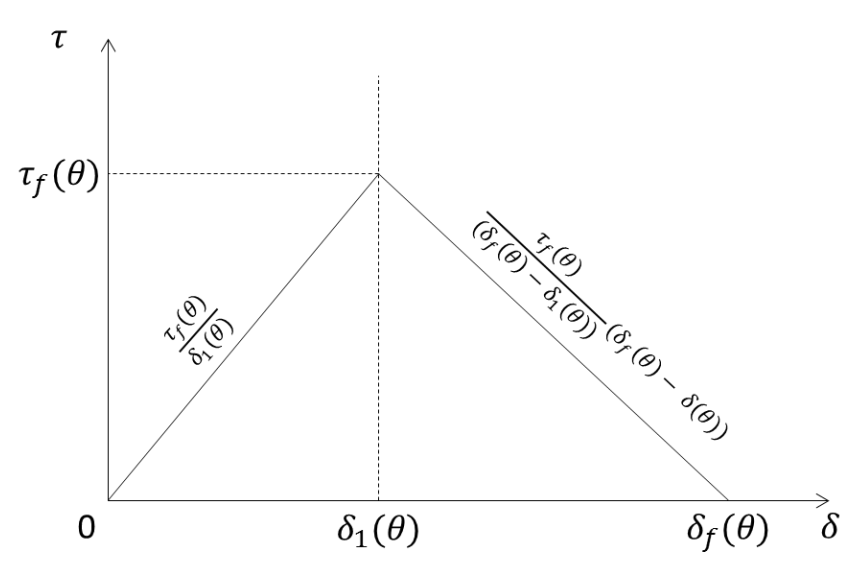

Fig. 3: Bilinear bond stress-anchor slip relationship

Consequently, by substituting the bilinear bond stress-anchor slip relationship (equation (9)) in equation (8), the differential equations of the shear-lag model become

$\frac{d^{2} \delta(x)}{d x^{2}}-\lambda^{2} \delta(x)=0 \quad$ for $\quad 0 \leq \delta(x)<\overline{\delta_{1}}$

and

$\frac{d^{2} \delta(x)}{d x^{2}}+\gamma^{2} \delta(x)=\gamma^{2} \overline{\delta_{f}} \quad$ for $\quad \overline{\delta_{1}} \leq \delta(x)<\overline{\delta_{f}}$

Where

$\lambda^{2}=\frac{2 \overline{\tau_{f}}}{\overline{\delta_{1}}}\left(\frac{1}{E^{s}}+\frac{A^{s}}{A^{c}} \cdot \frac{1}{E^{c}(\bar{\theta})}\right)$

$\gamma^{2}=\frac{2 \overline{\tau_{f}}}{\mathrm{R}\left(\overline{\delta_{f}}-\overline{\delta_{1}}\right)}\left(\frac{1}{E^{S}}+\frac{A^{s}}{A^{c}} \cdot \frac{1}{E^{c}(\bar{\theta})}\right)$

The terms $\lambda$ and $\gamma$, called "anchor parameters", regroup the geometrical and mechanical parameters of the anchor.

\section{1- Analytical approach}

For $0 \leq \delta(x)<\overline{\delta_{1}}$, the resolution of equation (10) provides the following expressions for the anchor slip, the bond stress and the axial stress respectively.

$\delta(x)=A \operatorname{ch}(\lambda x)+B \operatorname{sh}(\lambda x)$

$\tau(x)=\frac{\overline{\tau_{f}}}{\overline{\delta_{1}}}(A \operatorname{ch}(\lambda x)+B \operatorname{sh}(\lambda x))$

$\sigma^{S}(x)=\frac{2 \overline{\tau_{f}}}{R \lambda \overline{\delta_{1}}}(A \operatorname{sh}(\lambda x)+B \operatorname{ch}(\lambda x))$

For $\overline{\delta_{1}} \leq \delta(x)<\overline{\delta_{f}}$, the solution of equation (11) is of the form

$\delta(x)=C \sin [\gamma(x-L+a)]+D \cos [\gamma(x-L+a)]+\overline{\delta_{f}}$

$\tau(x)=\frac{\overline{\tau_{f}}}{\left(\overline{\delta_{f}}-\overline{\delta_{1}}\right)}(-C \sin [\gamma(x-L+a)]-D \cos [\gamma(x-L+a)])$

$\sigma^{S}(x)=\frac{2 \overline{\tau_{f}}}{R\left(\overline{\delta_{f}}-\overline{\delta_{1}}\right) \gamma}(C \cos [\gamma(x-L+a)]-D \sin [\gamma(x-L+a)])$

Where " $a$ " is the length of the partially damaged zone, $A, B, C$ and $D$ are the integration constants determined using boundary and continuity conditions. These conditions can be written as follows. 
- The axial stress at the bottom of the anchor is zero.

$\sigma^{S}(0)=0$

- The slip at the boundary between partially damaged and undamaged zone is equal to $\overline{\delta_{1}}$.

$\delta(L-a)=\overline{\delta_{1}}$

- The bond stress at the boundary between partially damaged and the undamaged zone is equal to $\overline{\tau_{f}}$.

$\tau(L-a)=\overline{\tau_{f}}$

- The axial stress is continuous at the crack tip.

$\sigma^{S}(L-a)^{-}=\sigma^{S}(L-a)^{+}$

Thus, using equation (20) we obtain $B=0$. Using equation (21) we obtain $A=\frac{\overline{\delta_{1}}}{\operatorname{ch}(\lambda(L-a))}$. Using equation (22), we found $D=\left(\overline{\delta_{1}}-\overline{\delta_{f}}\right)$. Finally, using equation (23) we obtain $C=\left(\overline{\delta_{f}}-\right.$ $\left.\overline{\delta_{1}}\right) \frac{\gamma}{\lambda} \tanh (\lambda(L-a))$.

Consequently, for $0 \leq \delta(x)<\overline{\delta_{1}}$,

$\delta(x)=\overline{\delta_{1}} \frac{\operatorname{ch}(\lambda x)}{\operatorname{ch}(\lambda(L-a))}$
$\tau(x)=\overline{\tau_{f}} \frac{\operatorname{ch}(\lambda x)}{\operatorname{ch}(\lambda(L-a))}$
$\sigma^{S}(x)=\frac{2 \overline{\tau_{f}}}{R \lambda} \frac{\operatorname{sh}(\lambda x)}{\operatorname{ch}(\lambda(L-a))}$

And for $\overline{\delta_{1}} \leq \delta(x)<\overline{\delta_{f}}$,

$\delta(x)=\left(\overline{\delta_{f}}-\bar{\delta}_{1}\right)\left[\frac{\gamma}{\lambda} \tanh (\lambda(L-a)) \sin [\gamma(x-L+a)]-\cos [\gamma(x-L+a)]\right]+\overline{\delta_{f}}$

$\tau(x)=-\overline{\tau_{f}}\left[\frac{\gamma}{\lambda} \tanh (\lambda(L-a)) \sin [\gamma(x-L+a)]-\cos [\gamma(x-L+a)]\right]$

$\sigma^{S}(x)=\frac{2 \overline{\tau_{f}}}{R \gamma}\left[\frac{\gamma}{\lambda} \tanh (\lambda(L-a)) \cos [\gamma(x-L+a)]+\sin [\gamma(x-L+a)]\right]$

Fig. 4 shows the bond stress profile at $\bar{\theta}=110^{\circ} \mathrm{C}$ determined by the analytical resolution of the shear-lag differential equation using the equations above. The length of the partially damaged zone of the bond " $a$ " is determined manually by determining the position of the anchor element showing the maximum bond stress value $\overline{\tau_{f}}$ for each loading level. Nevertheless, the new value of " $a$ " must be injected manually for each loading level in order to satisfy the continuity conditions presented by equations (21), (22) and (23). However, there is another way to overcome this continuity problem by piloting the shear-lag model in imposed displacement mode. Table 1 and Table 2 summarize respectively the geometric and mechanical parameters used to plot the bond stress distribution presented in Fig. 4.

\begin{tabular}{cc}
\hline \multicolumn{2}{c}{ Geometric parameters } \\
\hline $\mathbf{L}[\mathbf{m m}]$ & 120 \\
$\mathbf{R}[\mathbf{m m}]$ & 6 \\
$\mathbf{r}[\mathbf{m m}]$ & 75 \\
\hline
\end{tabular}

Table 1: Geometric parameters used in the calculation of the bond stress distribution 


\begin{tabular}{cc}
\hline$\overline{\boldsymbol{\theta}}\left[{ }^{\circ} \boldsymbol{C}\right]$ & 110 \\
\hline $\boldsymbol{E}^{\boldsymbol{s}}[\mathbf{G P a}]$ & 210 \\
$\boldsymbol{E}^{\boldsymbol{c}}[\mathbf{G P a}]$ & 26 \\
$\overline{\boldsymbol{\delta}_{\mathbf{1}}}[\mathbf{m m}]$ & 1.01 \\
$\boldsymbol{\delta}_{\boldsymbol{f}}[\mathbf{m m}]$ & 2.81 \\
$\overline{\boldsymbol{\tau}_{\boldsymbol{f}}}[\mathbf{M P a}]$ & 5.56 \\
$\mathbf{F}[\mathbf{k N}]$ & 24.8 \\
\hline
\end{tabular}

Table 2: Mechanical parameters used in the calculation of the bond stress distribution at $110^{\circ} \mathrm{C}$

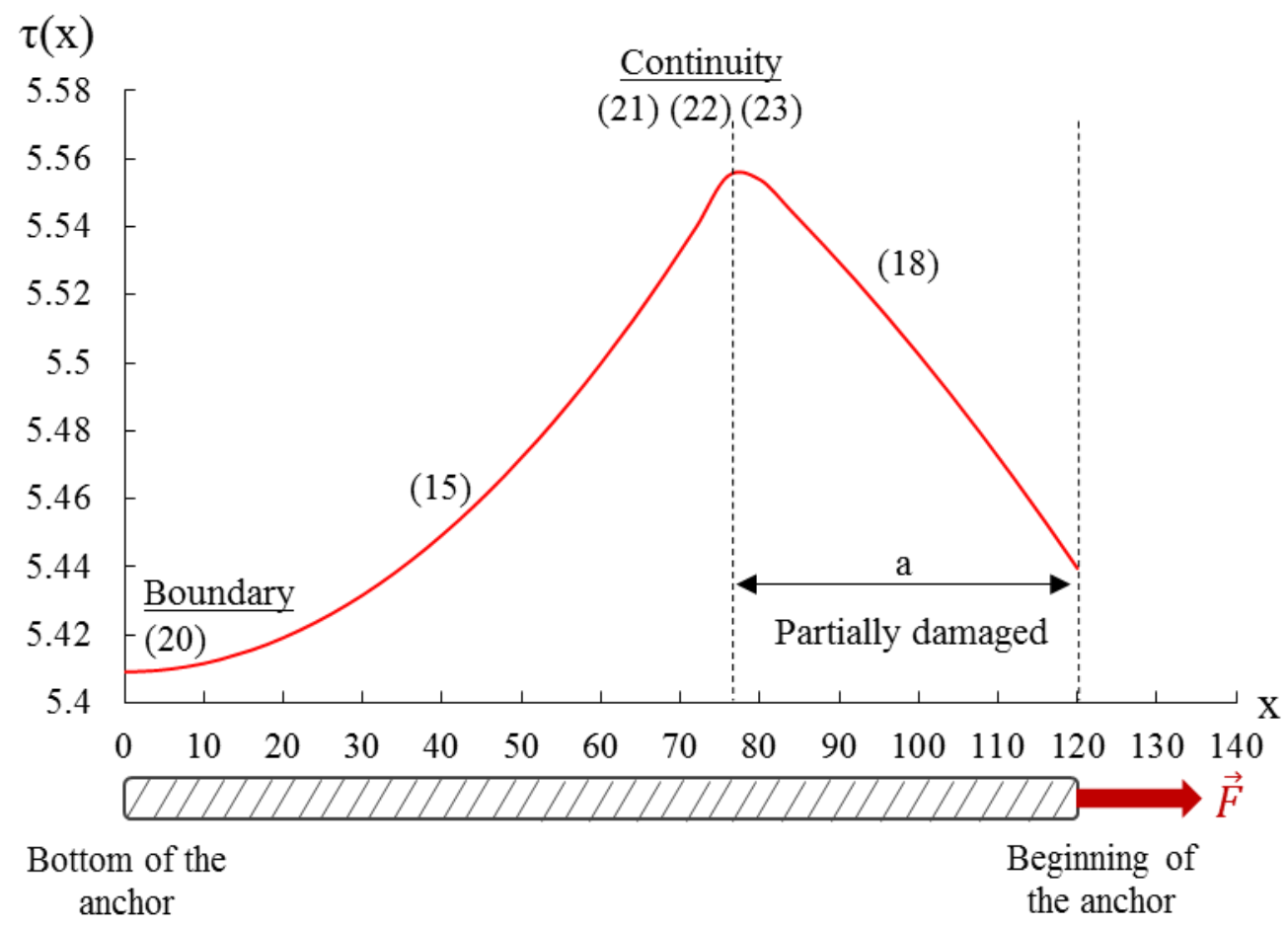

Fig 4: The use of boundary conditions in solving shear-lag equations

\section{2- Analytical approach with imposed displacement mode}

This section tends to adapt the shear-lag equations in order to study the stress distribution generated by an imposed displacement at the beginning of the anchor. Therefore, the solutions of the shear-lag differential equations become dependent on the boundary condition applied at the beginning of the anchor, as described by equation (30).

$\delta(x=L)=\left(\overline{\delta_{f}}-\overline{\delta_{1}}\right)\left[\frac{\gamma}{\lambda} \tanh (\lambda(L-a)) \sin [\gamma a]-\cos [\gamma a]\right]+\overline{\delta_{f}}=\overline{\delta_{\text {lmposed }}}$

Knowing $\overline{\delta_{\text {lmposed }}}$, it is possible to determine $\delta(x), \tau(x)$ and $\sigma(x)$ profiles using the equations (27), (28) and (29) in addition to continuity conditions. Finally, the length of the partially damaged zone" $a "$ can be determined automatically from the position of the element of the anchor exhibiting the maximum bond stress value, since the continuity conditions will always be satisfied in the case of imposed displacement mode.

\section{3- Numerical discretization}

This section presents the resolution of the shear-lag differential equations using the finite difference method (FDM). Indeed, the resolution of the shear-lag equations numerically using FDM allows studying complex cohesive laws, such the parabolic cohesive model, which cannot be solved 
analytically. Therefore, the anchor is discretized into $\mathrm{n}$ elements numbered from 1 to $\mathrm{n}$. Each element is of length $\Delta x$, chosen sufficiently small to assume a uniform bond stress distribution over the element. Each element has two borders, shared with the neighboring elements. The border between two successive elements of the anchor is denoted by an index i varying from 0 to $\mathrm{N}$. The border of index 0 corresponds to the beginning of the anchor and the border of index $\mathrm{N}$ corresponds to the bottom of the anchor. Three mechanical quantities are associated to each element and are $\delta_{i}, \tau_{i}$ and $\sigma_{i}^{s}$. These quantities are characteristic of the element and vary according to its temperature and to its position in the anchor. $\delta_{i}$ and $\sigma_{i}^{S}$ are expressed at the border indexed i, however $\tau_{i}$ is expressed over the element comprised between the borders indexed i and i+1 (Fig. 5).

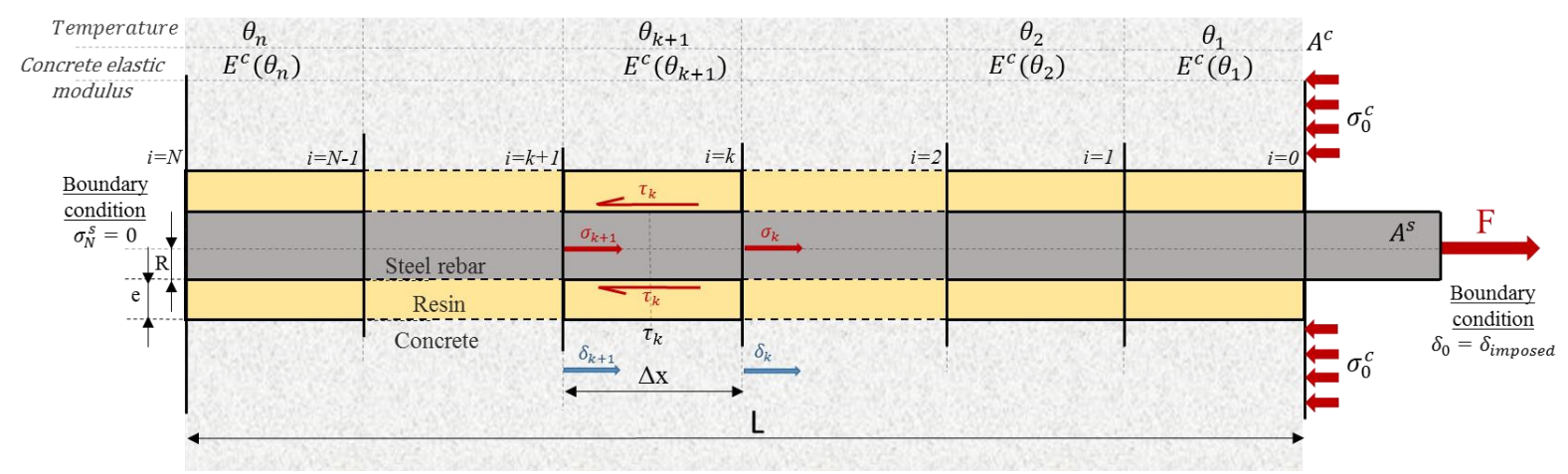

Fig. 5: Anchor discretization into n elements

The finite difference numerical model presented in this paper is designed to impose a displacement amount at the beginning of the anchor, as done in the previous section with the analytical model. Therefore, the resolution of the shear-lag differential equation is based on three boundary conditions.

- The amount of displacement at the beginning of the anchor is equal to the imposed displacement.

$\overline{\delta_{0}}=\overline{\delta_{\text {lmposed }}}$

- The amount of bond stress in the first element of the anchor is deduced from the amount of the imposed displacement using the bond stress-slip relationship.

$\overline{\tau_{0}}=f\left(\overline{\delta_{0}}\right)$

- The axial stress at the bottom of the anchor is equal to zero.

$\sigma_{N}^{S}=0$

Therefore, the discretization of the anchor into $\mathrm{n}$ elements requires the rewriting of the shear-lag equations according to the finite difference language as follows. Equation (34) is the adaptation of equation (2) to the finite difference language, allowing calculating the axial stress value at the border $i+1$. The axial stress at the border $i+1$ is equal to the axial stress value at the border $i$, decreased by the bond stress generated in the element $\mathrm{i}$.

$\overline{\sigma_{i+1, j}{ }^{s}}=\overline{\sigma_{i, j}{ }^{s}}-\left(\frac{2}{R} \overline{\tau_{i, j}} \Delta x\right)$

Equation (35) is derived from equation (5). The value of the slip at the border $i+1$ is equal to the slip at the border i minus the slip induced by the axial stress applied over the element $i+1$ (equal to the average axial stress between the borders $i$ and $i+1)$.

$\overline{\delta_{i+1, j}}=\overline{\delta_{i, j}}-\Delta x\left(\frac{1}{\bar{E}^{s}}+\frac{A^{s}}{A^{c} E^{c}(\bar{\theta})}\right)\left(\frac{\overline{\sigma_{i+1, j}^{s}}+\overline{\sigma_{i, j}}}{2}\right)$ 
Finally, the bond stress over the element $i+1$ is deduced from the slip at the border $i+1$ using equation (7). The adaptation of equation (7) to finite difference language corresponds to equation (36).

$\tau_{i+1, j}=f\left(\delta_{i+1, j}\right)$

The resolution of the shear-lag differential equation using the Finite Difference Method (FDM) with imposed displacement mode is done by iteration and is based on a convergence calculation ensuring the uniqueness of the solution. Therefore, an index $\mathrm{j}$ is introduced in the equations indicating the number of the convergence loop. Indeed, by solving numerically the equations (34), (35) and (36), the boundary condition $\sigma_{N}^{S}=0$ at the bottom of the anchor is not always satisfied. It is then necessary to re-estimate the value of $\sigma_{0}^{S}$ and to perform calculations several times until converging toward the boundary condition imposed at the bottom of the anchor. The estimation of the axial stress value at the beginning of the anchor $\sigma_{0}^{S}$ for each convergence loop is done according to a convergence criterion.

The convergence criterion suggested in this study is the False Position Method (called also Regula Falsi Method) [29]. Indeed, this method allows converging more quickly toward the desired solution as the suggested value at the loop $\mathrm{j}$ depends on the values estimated for the two previous loops $\mathrm{j}-1$ and $\mathrm{j}-2$.
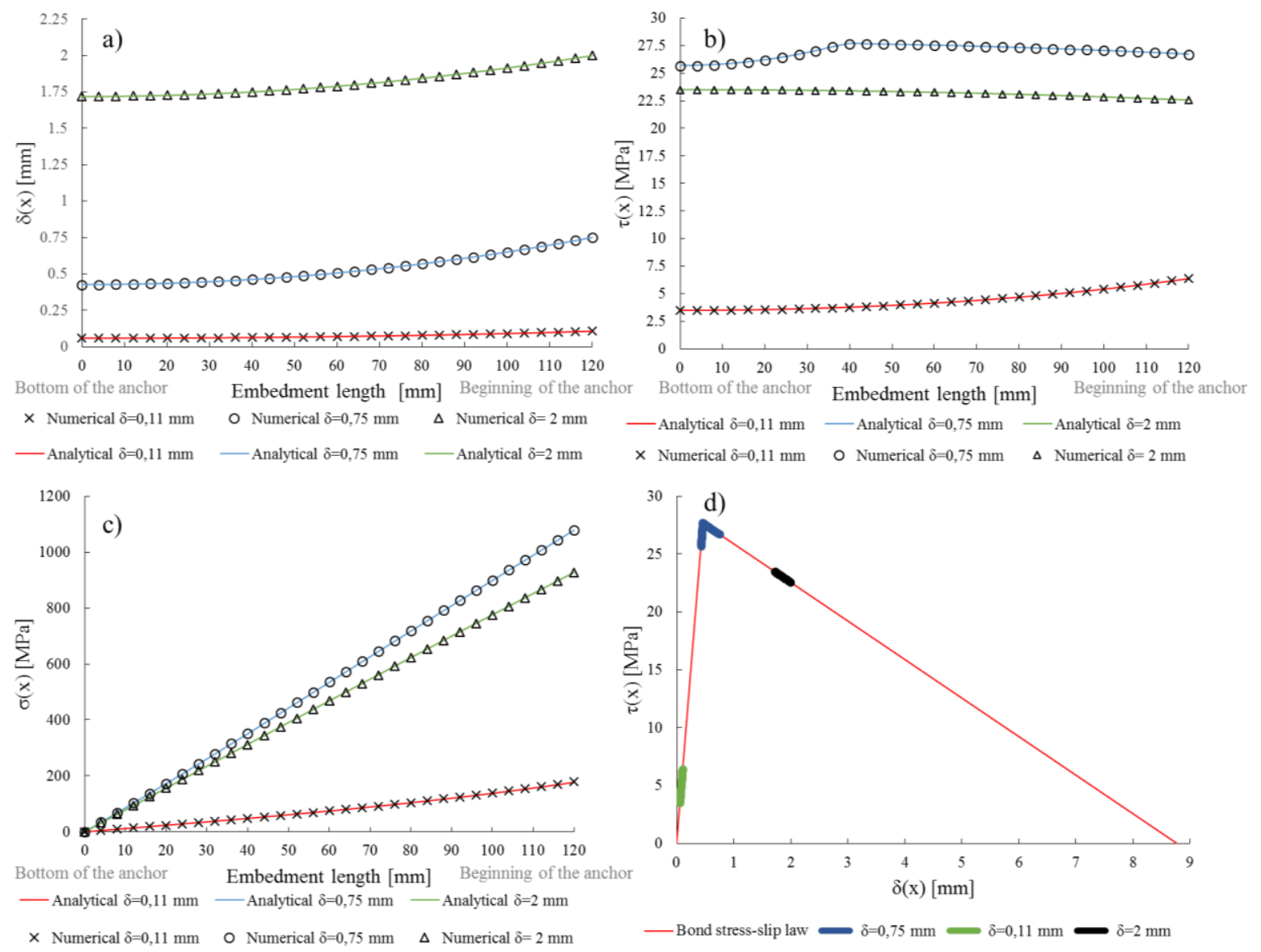

Fig. 6: Stress and slip profiles for different levels of imposed displacement obtained by analytical and finite difference models: a) Slip profile, b) Bond stress profile, c) Axial stress profile, $d$ ) Bond stress-slip cohesive law

Curves in Fig. 6 a), b) and c) represent respectively the axial stress, bond stress and the slip distribution along the anchor obtained analytically and numerically using the Finite Difference Method (FDM). These calculations are done for different levels of imposed displacement and for a uniform temperature distribution along the anchor $\left(\bar{\theta}=20^{\circ} \mathrm{C}\right)$. Geometric input data used in these calculations are the same as those presented in Table 1 . The mechanical input data are shown in Table 3. 


\begin{tabular}{lcccc}
\hline & $\boldsymbol{\delta}_{\text {imposed }}[\mathbf{m m}]$ & $\mathbf{0 . 1 0 6}$ & $\mathbf{0 . 7 5}$ & $\mathbf{2}$ \\
\hline & $\boldsymbol{E}^{\boldsymbol{s}}[\mathbf{G P a}]$ & 210 & 210 & 210 \\
& $\boldsymbol{E}^{\boldsymbol{c}}[\mathbf{G P a}]$ & 30 & 30 & 30 \\
Mechanical & $\overline{\boldsymbol{\delta}}_{\mathbf{1}}[\mathbf{m m}]$ & 0.46 & 0.46 & 0.46 \\
parameters & $\boldsymbol{\delta}_{\boldsymbol{f}}[\mathbf{m m}]$ & 8.77 & 8.77 & 8.77 \\
& $\overline{\boldsymbol{\tau}}_{\boldsymbol{f}}[\mathbf{M P a}]$ & 27.7 & 27.7 & 27.7 \\
& $\mathbf{F}[\mathbf{k N}]$ & 20 & 122 & 105 \\
\hline
\end{tabular}

Table 3: Mechanical input data used in the stress profiles calculations injected into the analytical and numerical models

The amount of imposed displacement generating the curves in Fig. 6 are $0.11 \mathrm{~mm}, 0.75 \mathrm{~mm}$ and $2 \mathrm{~mm}$. These displacement values generate an amount of axial force at the beginning of the anchor equal to 20 $\mathrm{kN}, 122 \mathrm{kN}$ and $105 \mathrm{kN}$ respectively. These displacement quantities allow describing the stress and slip profiles at three different mechanical states. Indeed, by imposing $0.11 \mathrm{~mm}$ displacement amount at the beginning of the anchor, the generated axial force is equal to $20 \mathrm{kN}$. For this amount of load, the anchor exhibits a reversible elastic mechanical behavior and the adhesive joint remains intact. However, by increasing the imposed displacement up to $0.75 \mathrm{~mm}$, the applied load at the beginning of the anchor increases to $122 \mathrm{kN}$, exceeding the bearing capacity of the anchor. Therefore, a crack forms and propagates in the bond joint. Calculations showed that for this quantity of applied load, the length of the bond damaged zone is equal to $a=80 \mathrm{~mm}$ from the beginning of the anchor. By increasing the imposed displacement up to $2 \mathrm{~mm}$, the crack continues to propagate over the entire length of the bond joint leading to its total damage.

Fig. 6 shows that the profiles obtained by analytical and numerical calculations are identical, which confirms the reliability of the Finite Difference numerical resolution method.

Curves in Fig. 6 a) expose the variation of the anchor slip for the three loading levels. Results show that the slip increases by increasing the imposed displacement at the beginning of the anchor. When the imposed displacement is small, the slip distribution exhibits a linear trend, which becomes exponential by increasing the imposed displacement.

Curves in Fig. 6 b) show the distribution profile of the bond stress along the adhesive joint. Results show that when the anchor is in the reversible elastic zone, the bond stress profile exhibits an exponential trend. For an axial load equal to $20 \mathrm{kN}$, the maximum value of the bond stress is reached at the beginning of the anchor and is equal to 6.4 MPa. However, the lowest stress value is equal to $3.5 \mathrm{MPa}$ and is located at the bottom of the anchor. By increasing the imposed displacement up to $0.75 \mathrm{~mm}$, the induced load exceeds the bearing capacity of the anchor leading to the bond damage over $80 \mathrm{~mm}$, as mentioned in the previous paragraph. The maximum bond stress is reached at the crack tip, and is equal to $\overline{\tau_{f}}$. The level of bond stress decreases in the damaged part and concentrates in the intact zone of the anchor, ensuring its resistance to the applied load. The increase in the imposed displacement up to $2 \mathrm{~mm}$ leads to the damage of the entire bond joint. Therefore, the anchor becomes no longer able to resist to the applied load and slips, generating a decay in the average bond stress.

Curves in Fig. 6 c) show the axial stress distribution for the three studied loading levels. Curves show that on the elastic zone, the axial stress profile presents an exponential trend, which becomes linear by increasing the load. Note here that for $\overline{\delta_{\text {lmposed }}}=0.75 \mathrm{~mm}$ and $\overline{\delta_{\text {lmposed }}}=2 \mathrm{~mm}$, the axial stress exceeds the steel yield stress, which is around $500 \mathrm{MPa}$ for a class B500A steel. In fact, this is due to the assumption of linearity of the adherents (assumption i, section 2.1), which does not fix a yield strength value for the adherents.

The curve in Fig. 6 d) shows the position of the anchor elements on the bond stress-slip cohesive law, used to describe the mechanical behavior of the bonded interface between the steel rebar and concrete. The curve shows that for $\overline{\delta_{\text {lmposed }}}=0.11 \mathrm{~mm}$, the entire anchor is located in the elastic reversible zone. 
However, when $\overline{\delta_{\text {lmposed }}}$ increases up to $0.75 \mathrm{~mm}$, the mechanical properties of the anchor are divided into two portions. A pre-peak portion, where the mechanical properties of the anchor still linear reversible, and a post-peak portion, where the bond is damaged and exhibits irreversible mechanical behaviour. For $\overline{\delta_{\text {lmposed }}}=2 \mathrm{~mm}$, the curve shows that the entire anchor is located in the damaged zone and therefore the more the imposed displacement increases, the more the average bond stress decreases.

\section{4- Temperature effect on the stress distribution profile}

In this section, the influence of a uniform temperature increase on the stress distribution along the anchor is examined. The temperature influence is assessed by comparing between the stress profiles for five different temperatures $\left(20^{\circ} \mathrm{C}, 40^{\circ} \mathrm{C}, 65^{\circ} \mathrm{C}, 80^{\circ} \mathrm{C}\right.$ and $\left.110^{\circ} \mathrm{C}\right)$. Slip profiles are calculated using equations (31) and (35). The axial and bond stress profiles are therefore derived from these two equations using equations (34) and (36), as explained in the previous section. For each studied temperature, an amount of displacement is imposed allowing generating the same amount of axial force at the beginning of the anchor equal to $25 \mathrm{kN}$. Table 4 summarizes the mechanical input data injected into the model. Geometrical input data are the same as those presented in Table 1.

\begin{tabular}{lcccccc}
\hline & & $\mathbf{2 0}^{\circ} \mathbf{C}$ & $\mathbf{4 0}^{\circ} \mathbf{C}$ & $\mathbf{6 5}^{\circ} \mathbf{C}$ & $\mathbf{8 0}^{\circ} \mathbf{C}$ & $\mathbf{1 1 0}^{\circ} \mathbf{C}$ \\
\hline \multirow{4}{*}{ Mechanical } & $\boldsymbol{\delta}_{\text {imposed }}[\mathbf{m m}]$ & 0.13 & 0.19 & 0.41 & 0.54 & 1.06 \\
parameters & $\boldsymbol{E}^{\boldsymbol{s}}[\mathbf{G P a}]$ & 210 & 210 & 210 & 210 & 210 \\
& $\boldsymbol{E}^{\boldsymbol{c}}[\mathbf{G P a}]$ & 30 & 29 & 28 & 27 & 26 \\
& $\overline{\boldsymbol{\delta}}_{\mathbf{1}}[\mathbf{m m}]$ & 0.46 & 0.61 & 0.96 & 0.88 & 1.01 \\
& $\overline{\boldsymbol{\delta}}_{\boldsymbol{f}}[\mathbf{m m}]$ & 8.77 & 7.89 & 7 & 4.87 & 2.81 \\
& $\overline{\boldsymbol{\tau}}_{\boldsymbol{f}}[\mathbf{M P a}]$ & 27.7 & 23.2 & 14.5 & 9.2 & 5.6 \\
\hline
\end{tabular}

Table 4: Input data used for the stress profiles calculations for different temperatures

The input data cited in Table 4 relating to the anchor mechanical parameters at high temperature $\left(\overline{\delta_{1}}\right.$, $\overline{\delta_{f}}$ and $\overline{\tau_{f}}$ ) are obtained by pull-out tests performed at the studied temperatures. The concrete elastic modulus variation as a function of temperature is provided by the Eurocode 2, part 1-2 [25]. 

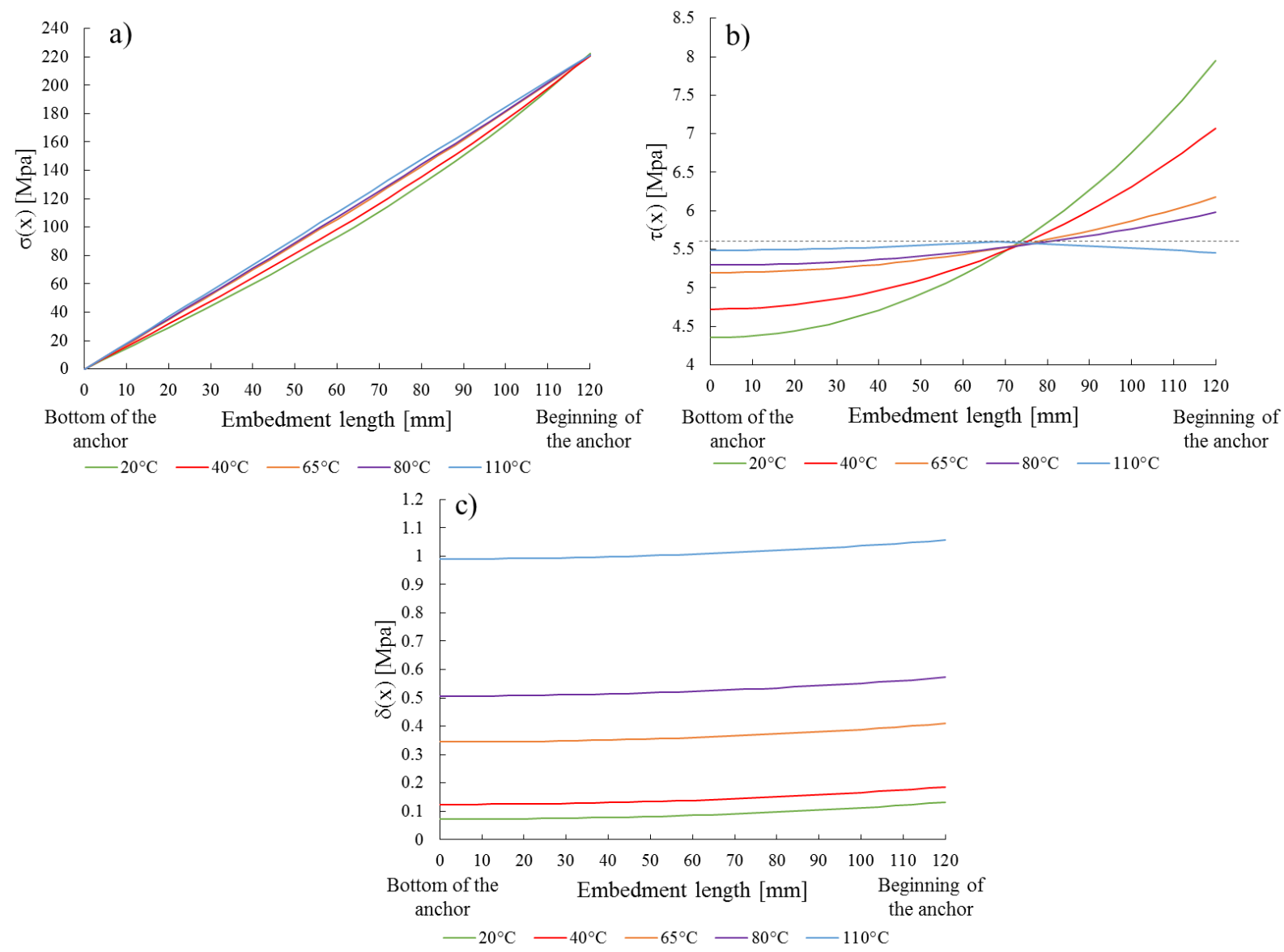

Fig. 7: a) Axial stress, b) bond stress, c) Anchor slip profiles at different temperatures obtained using the analytical shear-lag solution

Curves in Fig. 7 show the stress and slip distribution along the anchor at different temperatures. Fig. 7 a) shows that the axial stress profile presents an exponential trend when temperatures are close to ambient temperature. However, by increasing the anchor temperature, the axial stress profile tends to become linear. Based on equation (2), the linearization of the axial stress profile at high temperature leads to a uniform bond stress distribution along the anchor, which is confirmed in Fig. $7 \mathrm{~b}$ ). Indeed, the analysis of the bond stress profiles at different temperatures shows that for temperatures close to ambient temperature, the bond stress distribution exhibits an exponential trend. However, by increasing the anchor temperature, this distribution becomes uniform.

Fig. $7 \mathrm{~b}$ ) shows that, for the same loading level, the increase of the anchor temperature up to $110^{\circ} \mathrm{C}$ leads to the partial damage of the bond joint. The bond damage is manifested by the local decay in the bond stress value on the damaged zone, as highlighted by the dashed line on Fig. 7 b). The bilinear shear-lag model shows that for $25 \mathrm{kN}$ axial force applied at the beginning of the anchor and for an anchor temperature equal to $110^{\circ} \mathrm{C}$ uniformly distributed, the bond joint presents a damaged zone equal to 52 $\mathrm{mm}$.

In addition, results in Fig. 7 c) show that the temperature increase leads to increase the anchor slip. Indeed, this can be explained by the fact that the anchor temperature increase leads to a decay in the mechanical properties of the resin, such as its shear modulus [28] [30], which therefore leads to decrease the anchor stiffness. Consequently, the temperature increase leads to increase the anchor slip.

To conclude, the shear-lag model shows that a uniform temperature increase affects the stress distribution along the anchor by the linearization of the axial stress distribution and by making the bond 
stress uniformly distributed over the anchor. However, the increase in the temperature of the anchor may lead, under certain conditions, to the damage of the bond joint.

\section{Case of a non-uniform temperature distribution}

This section presents the resolution of the shear-lag equation (equation (8)) in the general case, i.e. for any temperature distribution along the anchor. A set of curves describing the relationship between the adhesive bond stress and the anchor slip at different temperatures are used as input data. These curves are obtained experimentally by performing pull-out tests at stabilized temperature on steel rebars chemically bonded into concrete. These tests were carried out at several temperatures varying between $20^{\circ} \mathrm{C}$ and $130^{\circ} \mathrm{C}$. The test procedure is described in a previous paper [28]. The experimental curves are shown in Fig. 8.

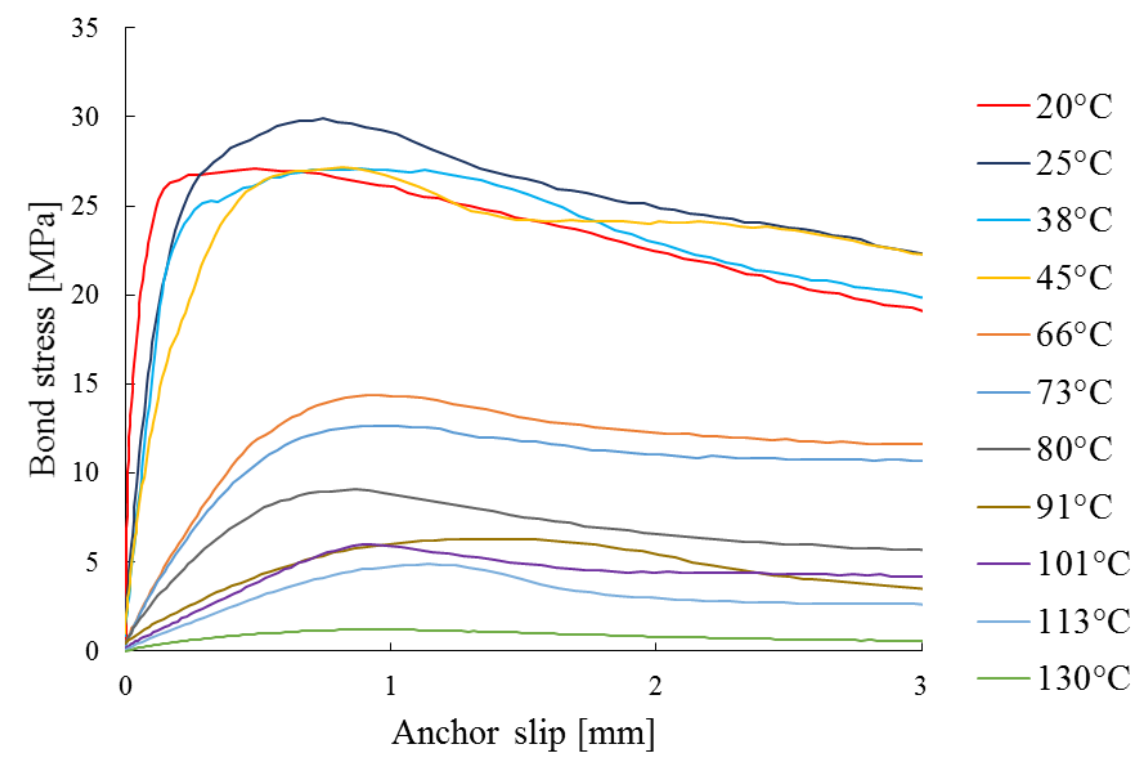

Fig. 8: Bond stress - anchor slip curves obtained by pull-out tests at different temperatures

The approximation of the curves in Fig. 8 using a bilinear bond stress - anchor slip law allows the resolution of the shear-lag equations analytically but does not describe adequately the mechanical behavior of the anchor at different temperatures, as shown in Fig. 9. Consequently, in the rest of this study, the bond stress - anchor slip curves will be fitted using the Model Code 2010 (MC2010) [31] described by equation (37). Indeed, the MC2010 is a cohesive law combining the parabolic, perfect rigid-plastic and bilinear laws. It divides each pull-out curve, presented in Fig.8, into four portions.

- A first portion, representing the reversible elastic mechanical behavior of the anchor, described by a parabolic equation. The coefficient $\alpha(0 \leq \alpha \leq 1)$ allows modeling all usual forms of a bond stress - slip relationship ( $\alpha=0$ for a constant stress, $\alpha=1$ for bond stress-slip relationship with $\underline{\text { linear increasing bond stress) }}$

- A second portion described by a constant, equal to the maximum resistance of the anchor. On this portion, the adhesive bond stress remains constant when increasing the anchor displacement.

- A linear portion describing the damage of the bond joint. Over this portion, the increase in the anchor slip leads to reduce the amount of the bond stress applied at the interface between the steel rebar and concrete.

- Finally, a constant portion, equal to the residual resistance of the anchor, generated by the friction between steel rebar and concrete. In this study, the residual anchor resistance in chosen equal to zero. 


$$
\tau(\delta(x), \theta(x))= \begin{cases}\tau_{\max }(\theta)\left(\frac{\delta(x, \theta)}{\delta_{1}(\theta)}\right)^{\alpha(\theta)} & \text { when } 0 \leq \delta(x, \theta) \leq \delta_{1}(\theta) \\ \tau_{\max }(\theta) & \text { when } \delta_{1}(\theta)<\delta(x, \theta) \leq \delta_{2}(\theta) \\ \frac{\tau_{\max }(\theta)}{\delta_{2}(\theta)-\delta_{3}(\theta)}\left(\delta(x, \theta)-\delta_{2}(\theta)\right)+\tau_{\max }(\theta) & \text { when } \delta_{2}(\theta)<\delta(x, \theta) \leq \delta_{3}(\theta) \\ 0 & \text { when } \delta(x, \theta)>\delta_{3}(\theta)\end{cases}
$$

In addition, in the case of a non-uniform temperature distribution, the term $\lambda$ (anchor parameter) represented previously in equation (12) becomes temperature-dependent, and therefore dependent on the $x$ position of the anchor element. Consequently, it is no longer easy to solve the shear-lag equations analytically, and therefore it is more relevant to use a numerical model. Thus, the shear-lag equations are solved numerically using the finite difference model (FDM) presented in section 3.3. The FDM equations used to solve the shear-lag equations are identical to those used for a uniform temperature distribution and described by equations (34), (35) and (36).

Fig. 9 shows the approximation of pull-out curves using the bilinear cohesive law and the MC2010. For the clarity of the graph, only a few pull-out curves are shown in Fig. 9. Comparisons show that the error between experimental curves and MC2010 is close to 5\%, which proves that the MC2010 describes better the mechanical behavior of chemical anchors at different temperatures than the bilinear law. Table 5 summarizes the variation of the mechanical parameters of the anchor at different temperatures, extracted from the whole curves shown in Fig. 8 using the MC2010. These parameters are specific to the resin used in making the anchor and will be injected in the shear-lag model to calculate the stress distribution profile for the general case of temperature distribution.

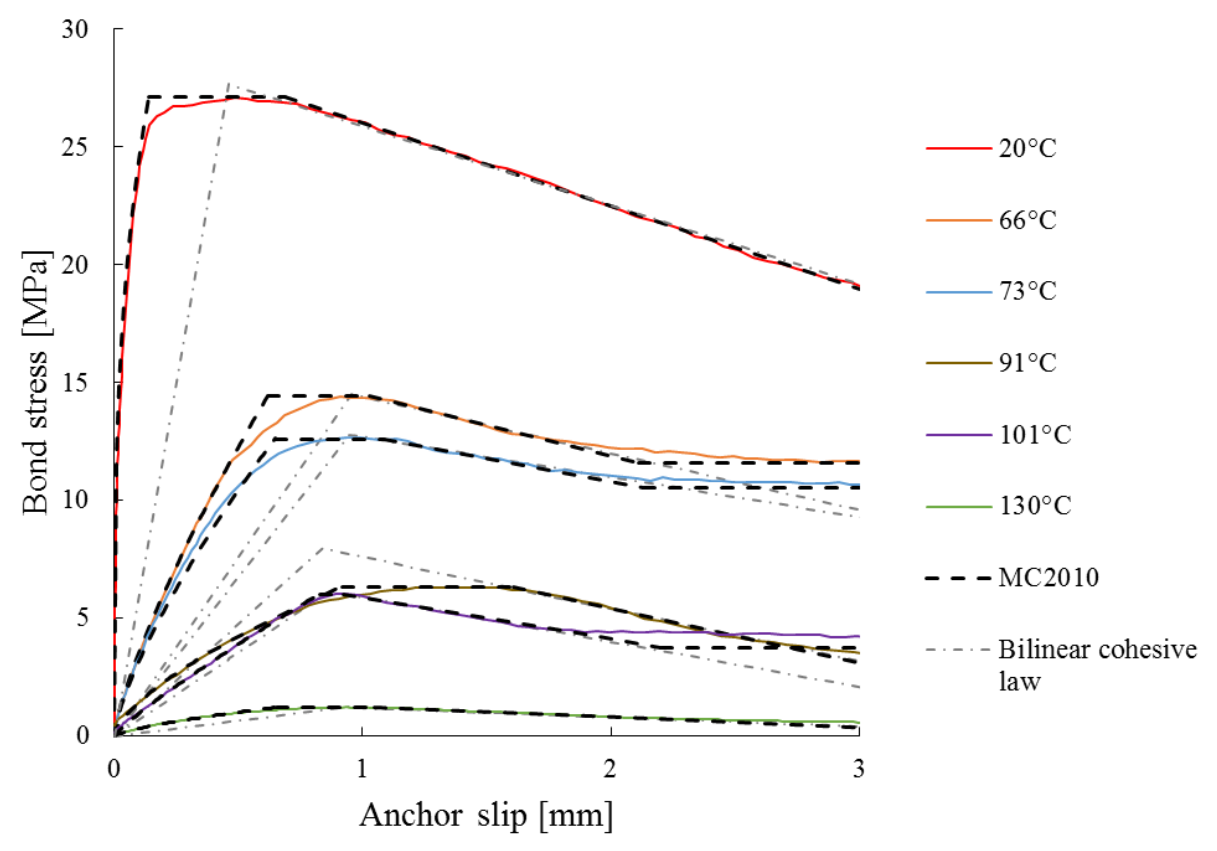

Fig. 9: Experimental and MC2010 pull-out curves for different temperatures 


\begin{tabular}{cccccc}
\hline $\boldsymbol{\theta}\left[{ }^{\circ} \mathbf{C}\right]$ & $\boldsymbol{\tau}_{\mathbf{m a x}}[\mathbf{M P a}]$ & $\boldsymbol{\delta}_{\mathbf{1}}[\mathbf{m m}]$ & $\boldsymbol{\delta}_{\mathbf{2}}[\mathbf{m m}]$ & $\boldsymbol{\delta}_{\mathbf{3}}[\mathbf{m m}]$ & $\boldsymbol{\alpha}$ \\
\hline 20 & 27.1 & 0.1 & 0.7 & 6.1 & 0.3 \\
25 & 29.9 & 0.2 & 0.8 & 6.7 & 0.7 \\
38 & 27.2 & 0.2 & 1.1 & 6.8 & 0.6 \\
45 & 27.2 & 0.5 & 0.9 & 6.3 & 0.4 \\
66 & 14.4 & 0.6 & 1 & 2.1 & 0.8 \\
73 & 12.6 & 0.7 & 1.1 & 2.1 & 0.7 \\
80 & 9.1 & 0.7 & 0.9 & 2.6 & 0.6 \\
91 & 6.4 & 0.9 & 1.6 & 3.3 & 0.7 \\
101 & 6 & 0.8 & 0.9 & 2.2 & 0.9 \\
113 & 4.9 & 0.9 & 1.2 & 1.9 & 0.9 \\
130 & 1.2 & 0.7 & 1.1 & 3.2 & 0.7 \\
\hline
\end{tabular}

Table 5: Anchor mechanical parameters for different temperatures extracted from experimental curves using MC2010 law

The remainder of this section presents the adaptation of the shear-lag model to a concrete structure containing chemical anchors exposed to ISO 834-1 fire until its collapse. The shear-lag model will be used further to predict the fire resistance duration of this structure. The structure is composed of a 2.94 $\mathrm{m} \times 2 \mathrm{~m} \times 0.15 \mathrm{~m}$ cantilever concrete slab, connected to a concrete wall using 8 bonded rebars. The steel rebars are of diameter $16 \mathrm{~mm}$, anchored in the concrete wall using the same epoxy resin used for pullout tests (Fig. 8). The embedment length of the chemical anchors is set at $135 \mathrm{~mm}$. The concrete slab is mechanically loaded by a $325 \mathrm{~kg}$ dead weight positioned at $2.2 \mathrm{~m}$ from the surface of the wall, and thermally loaded following the standard ISO 834-1 fire curve [25] until collapse. Thermal calculations carried out by finite element analysis using Cast $3 \mathrm{M}$ software and concrete thermal properties provided by the Eurocode [25] allowed to reproduce the propagation of the temperature along the anchors at different times of ISO fire exposure (Fig. 10). The obtained thermal profiles will then be injected into the shear-lag model to calculate the evolution of the bearing capacity of chemical anchors. In other situations, it is possible to determine temperature profiles with other methods than EC2. These temperatures are used as entry data for the shear-lag model and are not coupled to the mechanical step.

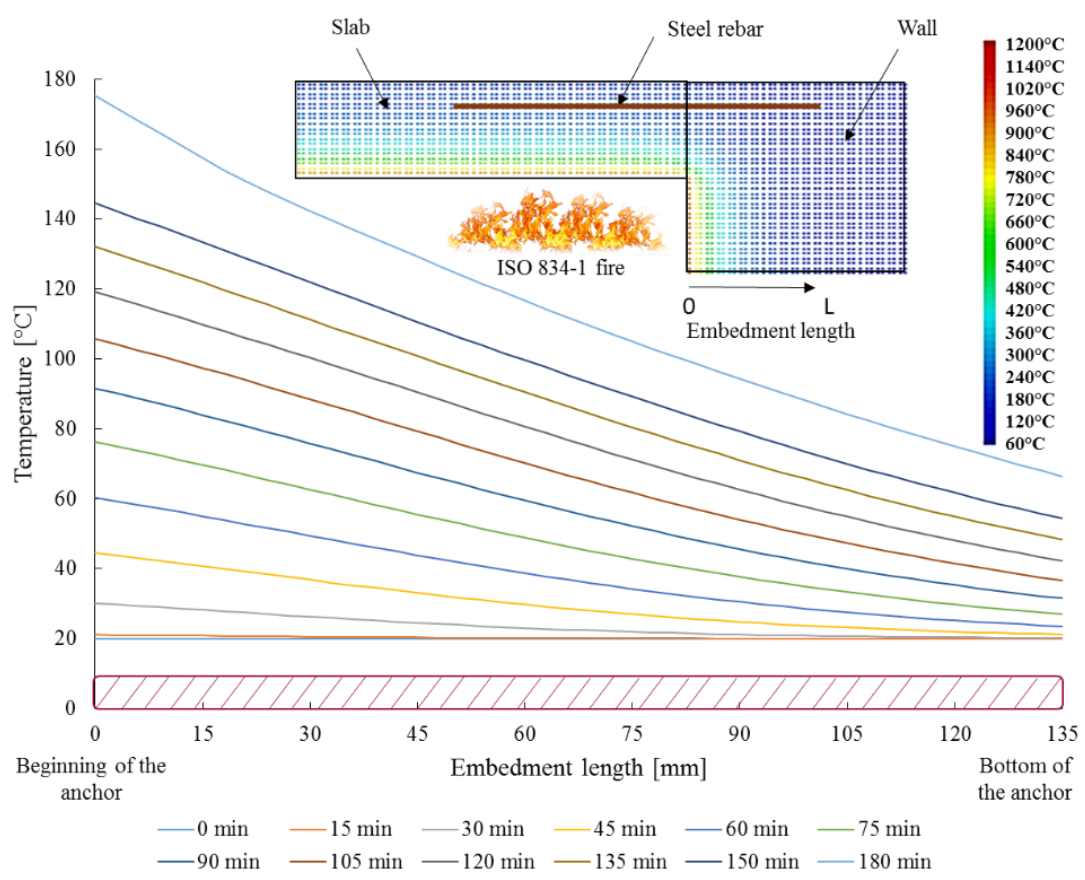

Fig. 10: Evolution of the temperature distribution along the anchor during the ISO 834-1 fire exposure 
Analytical mechanical calculations carried out on the studied configuration showed that the load applied on each chemical anchor is around $48 \mathrm{kN}( \pm 3 \mathrm{kN})$. This amount of tensile load will make it possible to determine the moment from which the bearing capacity of the anchors becomes lower than the applied load and hence, will be a key factor in the prediction of the fire resistance of the studied structure using the shear-lag model.

In this case study, the anchor is divided into 46 elementary elements in the shear-lag model. The length of each element is $\Delta x=3 \mathrm{~mm}$. Temperature profiles presented in Fig. 10 show that the exposure of the structure to the ISO 834-1 fire leads to the creation of a thermal gradient along the anchor. After 90 minutes of ISO fire exposure, the beginning of the anchor exhibits the highest temperature, around $92^{\circ} \mathrm{C}$, while the bottom exhibits the lowest temperature, around $31^{\circ} \mathrm{C}$. The thermal gradient leads to the modification of the mechanical properties of the anchor elements [32]. Curves in Fig. 11 represents the bond stress - anchor slip relationship in each element composing the anchor for 90 minutes of ISO fire exposure. Curves show that for low temperatures, the anchor elements exhibit high stiffness and bond resistance. However, the increase in the element temperature leads to a decay in its stiffness and in its bond resistance. The curves also show that the amount of slip needed to reach the yield strength of the anchor element $\left(\delta_{1}\right)$ increases by increasing the temperature due to the stiffness decay under the temperature effect. Nevertheless, the amount of slip leading to the pull-out of the anchor $\left(\delta_{2}\right)$ decreases when temperature increases due to the decrease of the bond resistance.

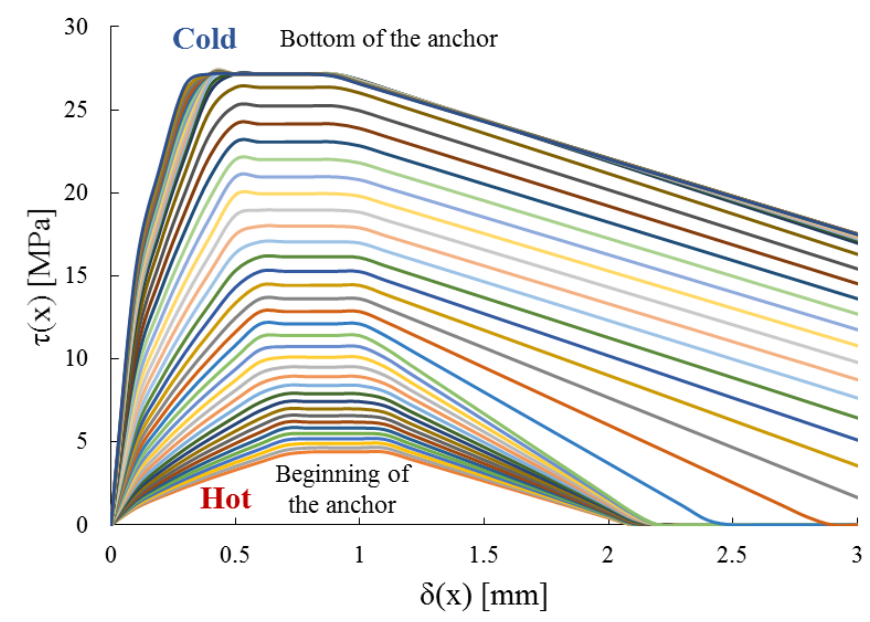

Fig. 11: Bond stress-slip relationship determined by interpolation of experimental parameters in table 5 for 90 minutes of ISO fire exposure

Curves in Fig. 12 a) show the variation of the anchor constitutive law (vertical curves), governing the mechanical behavior of the anchor, and induced by four different axial forces reflecting four different mechanical states. Each constitutive law is composed from the position of each element of the anchor on the adhesive bond stress-slip curves, presented in light color in Fig. 12 a). Note that these bond stress-slip curves are identical to those shown in Fig. 11, relative to a thermal profile generated by the exposure of the studied structure to the ISO fire for 90 minutes. 

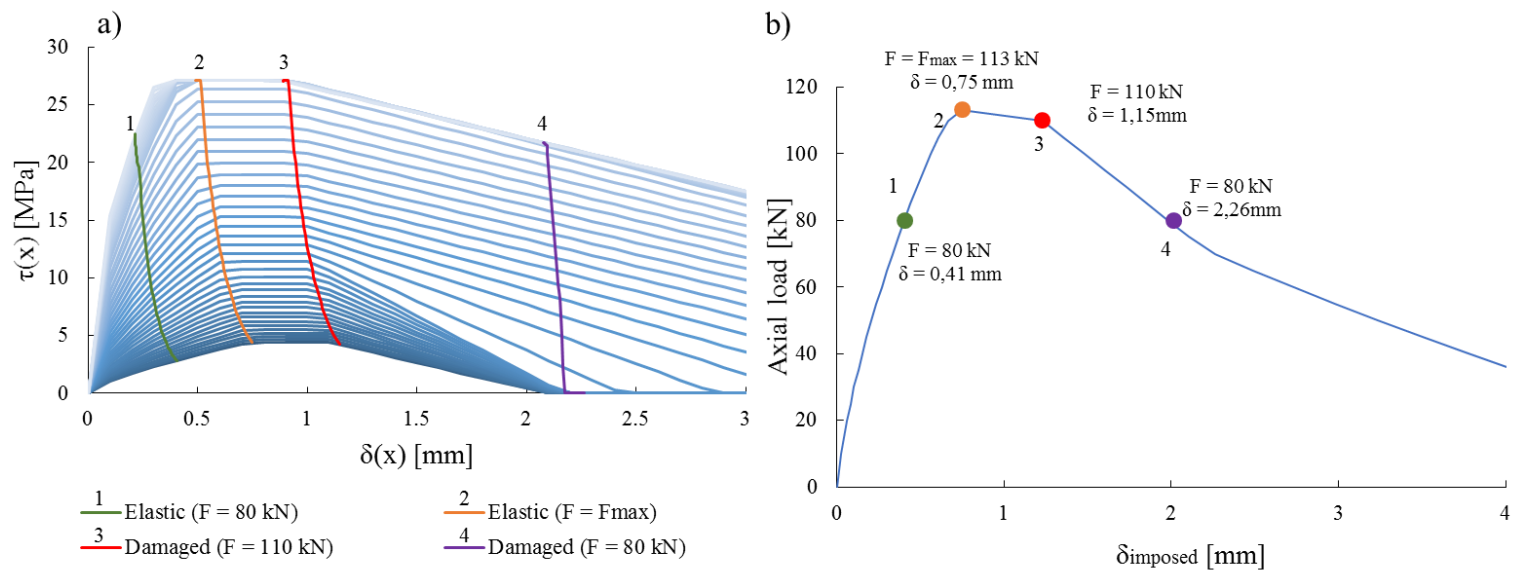

Fig. 12: a) Anchor constitutive law variation for different loading levels. b) Theoretical axial force-anchor slip curve obtained by the shear-lag model for 90 minutes ISO fire exposure

The first vertical curve $\left(\mathrm{N}^{\circ} 1\right.$-Elastic $\left.(\mathrm{F}=80 \mathrm{kN})\right)$ describes the anchor constitutive law for an imposed displacement equal to $0.41 \mathrm{~mm}$, generating $80 \mathrm{kN}$ axial force at the beginning of the anchor. For this amount of imposed displacement, the curve shows that all the anchor elements are in the elastic reversible mechanical zone. By increasing the imposed displacement up to $0.75 \mathrm{~mm}$, the anchor reaches its yielding limit and the generated axial force applied at the beginning of the anchor reaches the load bearing capacity of the anchor $\left(F_{\max }\right)$. Curve $\mathrm{N}^{\circ} 2$ in Fig. 12 a) shows that for $\mathrm{F}=\mathrm{F}_{\max }=113 \mathrm{kN}$, the anchor elements still in the reversible elastic zone, but reach their yielding limit at the same moment. This observation is very important and allows confirming that before the bond damage, all the anchor elements provide their maximum performance. This conclusion will be elaborated in the following section.

The increase of the imposed displacement beyond $0.75 \mathrm{~mm}$ leads to the damage of the bond. The third vertical curve in Fig. 12 a) shows the position of the anchor constitutive law for an imposed displacement value equal to $1.15 \mathrm{~mm}$ generating an axial force equal to $110 \mathrm{kN}$. For this displacement value, at least a portion of the adhesive bond joint should be damaged. Indeed, the third curve in Fig. 12 a) shows that the elements at the beginning of the anchor (hot part) are located on the third zone of the bond stress slip curves, reflecting the damage of the bond joint. At the same time, the elements at the bottom of the anchor (cold part) are located on the plastic plateau, and therefore do not present any damage. Consequently, the anchor is damaged only in its beginning. Calculations carried out using the numerical FDM shear-lag model show that the bond joint presents, for this amount of imposed displacement, 33 $\mathrm{mm}$ of damage length.

The last vertical curve in Fig. 12 a) describes the constitutive law of the anchor for an imposed displacement equal to $2.26 \mathrm{~mm}$. For this amount of displacement, Fig. 12 a) shows that the totality of the anchor elements are located on the mechanical zone describing the damage of the bond. Nevertheless, the axial force generated by the imposed displacement is not zero and is around $70 \mathrm{kN}$. Indeed, despite the damage of the entire bond joint, the anchor continues to resist to the applied load by friction with concrete surface until its pull-out, which explain the residual axial force presented in the damaged anchor [28].

Curve in Fig. 12 b) shows the theoretical variation of the axial force as a function of the displacement imposed at the beginning of the anchor after 90 minutes of ISO fire exposure. The curve shows that the anchor exhibits a linear elastic behavior until reaching $\mathrm{F}_{\max }$ corresponding to an imposed displacement equal to $0.74 \mathrm{~mm}$. It was possible, using this curve, to calculate the global stiffness of the anchor for 90 minutes of ISO fire exposure, which is found equal to $183 \mathrm{kN} / \mathrm{mm}$. By increasing the imposed displacement, the anchor exhibits a constant axial force caused by the yielding of the bond joint, until reaching $1.149 \mathrm{~mm}$. Beyond this displacement value, the bond is damaged and the axial force generated 
at the beginning of the anchor decreases progressively until the total pull-out of the anchor. The points presented on this curve indicate the position of the four mechanical states studied in Fig. 12 a).
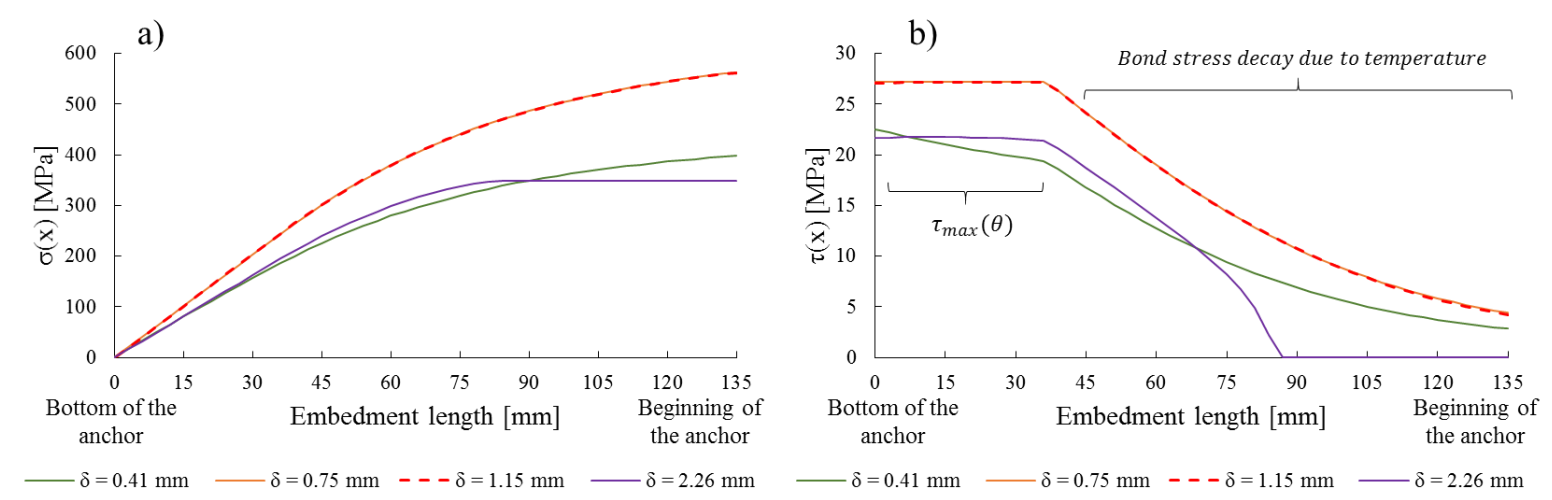

c)

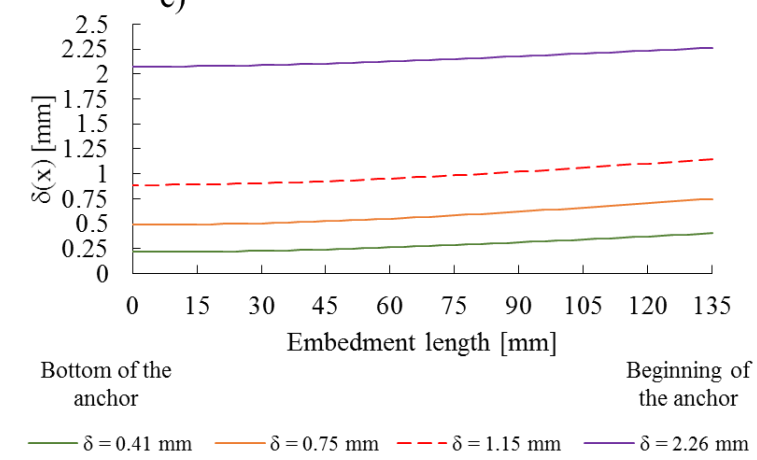

Fig. 13: a) Axial stress, b) bond stress and c) Anchor slip distribution in case of a thermal gradient for different imposed displacement values

Curves in Fig 13 a), b) and c) describe respectively the axial stress, the bond stress and the anchor slip distribution for the four imposed displacement values studied in this section and for a thermal profile generated by 90 minutes ISO fire exposure. Curves in Fig. 13 a) show that under a thermal gradient effect, the axial stress profile exhibits a logarithmic trend, unlike the case of a uniform temperature distribution. The increase in the displacement imposed at the beginning of the anchor increases the axial stress transferred to the anchor until reaching a maximum value. When the maximum axial stress value is reached, the bond joint yields and the axial stress distribution along the anchor remains the same as well as all the elements composing the anchor still located on the plastic plateau.

Fig. $13 \mathrm{a}$ ) and b) show that for $\delta_{\text {imposed }}=0.75 \mathrm{~mm}$ and $\delta_{\text {imposed }}=1.15 \mathrm{~mm}$, the axial and bond stress profiles are virtually identical. Indeed, as explained previously, for $\delta_{\text {imposed }}=1.15 \mathrm{~mm}$, only the anchor elements positioned at $33 \mathrm{~mm}$ length from the beginning of the anchor are damaged, while the rest of the anchor elements are located on the plastic plateau. Consequently, for $\delta_{\text {imposed }}=0.75 \mathrm{~mm}$ and $\delta_{\text {imposed }}=1.15 \mathrm{~mm}$, the axial and bond stress distribution profiles still close. However, the increase of $\delta_{\text {imposed }}$ up to $2.26 \mathrm{~mm}$ leads to the total damage of the bond. Curve in Fig. $13 \mathrm{~b}$ ) relative to $\delta_{\text {imposed }}=$ $2.26 \mathrm{~mm}$ shows that only about $87 \mathrm{~mm}$ of the anchor continue to resist to the imposed axial force by friction with the concrete surface, whereas the elements present at the first $48 \mathrm{~mm}$ of the anchor exhibit a zero bond stress value.

It is important to note from Fig. $13 \mathrm{~b}$ ) that unlike the case of a uniform temperature distribution, the presence of a thermal gradient along the anchor leads to a bond stress concentration in the coldest zones of the anchor, i.e. in the bottom of the anchor. This observation is valid even when all the elements composing the anchor are in the linear elastic mechanical zone. 


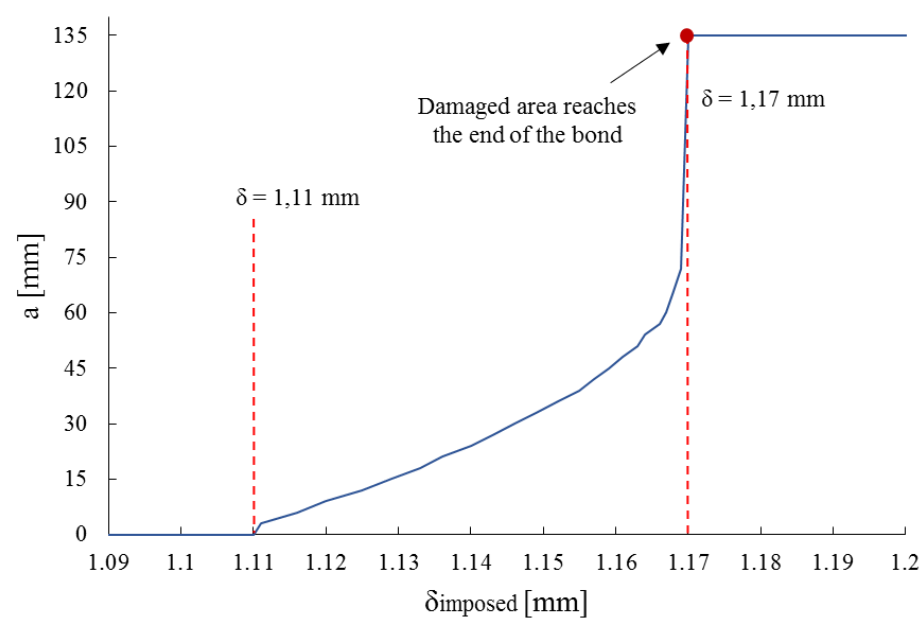

Fig. 14: Damage propagation as a function of the displacement imposed at the beginning of the anchor

The curve in Fig. 14 describes the damage propagation along the bond joint as a function of the displacement imposed at the beginning of the anchor. The curve shows that the initiation of the damage starts as soon as the imposed displacement reaches the value of $1.11 \mathrm{~mm}$. From this displacement value, the damaged propagates along the bond linearly up to $\delta_{\text {imposed }}=1.16 \mathrm{~mm}$. By reaching $1.16 \mathrm{~mm}$, the damage propagation is accelerated. Fig. 14 shows that when the length of the damaged zone becomes equal to $72 \mathrm{~mm}$ (for $\delta_{\text {imposed }}=1.17 \mathrm{~mm}$ ), the damage propagates brutally over the entire remaining embedment length.

\section{Model validation and comparison with the resistance integration method}

The aim of this section is to assess the capacity of the model to predict the fire resistance duration of adhesively bonded anchors. Thus, the work consists in comparing the model results with the experimental results. For this purpose, a full-scale fire test was performed on the Vulcain furnace of CSTB (Champs-sur-Marne, France) on the same structure described in section 4 (Fig. 15). The test specimen was instrumented by thermocouples, displacement sensors, digital stereo images correlation system and inclinometers, in order to study the phenomena occurring in the structure during fire exposure. The fire test highlighted a vertical displacement of the slab towards the outside of the furnace during the first minutes of the test, caused by the differential thermal expansion due to the large thermal gradient present between the exposed and non-exposed surfaces of the slab. Starting from the $28^{\text {th }}$ minute of fire test, the slab started falling progressively inside the oven and collapsed exactly after 117 minutes of ISO fire exposure. Finally, the fire test allowed to measure the real fire resistance duration of the studied structure, and showed that the collapse was mainly caused by the rebars sliding under the effect of heat. The load applied to each anchor was determined analytically and was around $48 \mathrm{kN}( \pm 3 \mathrm{kN})$. 


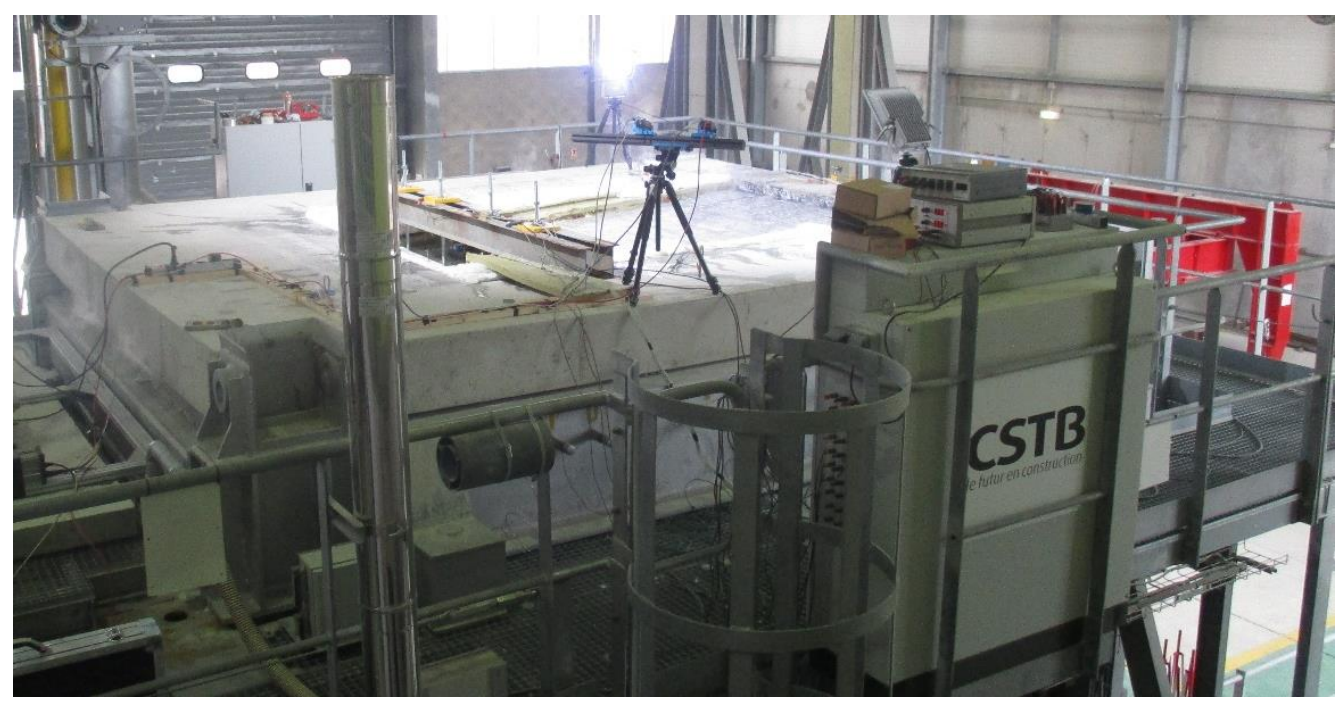

Fig. 15: Full-scale fire test on a concrete cantilever slab connected to a concrete wall by chemical anchors performed on the Vulcain furnace (CSTB, Champs-sur-Marne, France)

Details of instrumentation, phenomena interpretation and mechanical and thermal calculations are presented in another paper dedicated to the full-scale fire test performed on the studied cantilever concrete slab (under review).

Fig. 16 presents the evolution of the anchor fire resistance during the exposure of the studied structure to the ISO 834-1 fire. The fire resistance curves shown in Fig. 16 are plotted by determining the maximum axial force supported by the anchor at different times of fire exposure calculated using the numerical shear-lag and the resistance integration models. In fact, the calculation of the anchor load bearing capacity at a time $t$ of fire exposure, using the shear-lag model, consists in determining the maximum axial force reached considering a thermal profile relative to a given time of fire exposure (taking into account the bond stress-slip relationship). The determination of the anchor load bearing capacity at time $t$ using the resistance integration method is detailed in separate paper. It consists in integrating, over the entire embedment length, the maximum resistance $\tau_{\max }$ of all elements of the anchor, generated by the corresponding thermal profile. This method is used for the fire design of chemical anchors according to the EAD 330087-00-0601 [33].

Fig. 16 shows that the values of the anchor load bearing capacity provided by the shear-lag model and by the resistance integration method are close. Indeed, as noted in section 4 , when the anchor reaches its bearing capacity, all the anchor elements reach their maximum bond stress $\tau_{\max }$ at the same time. Consequently, the two methods provide close results. 


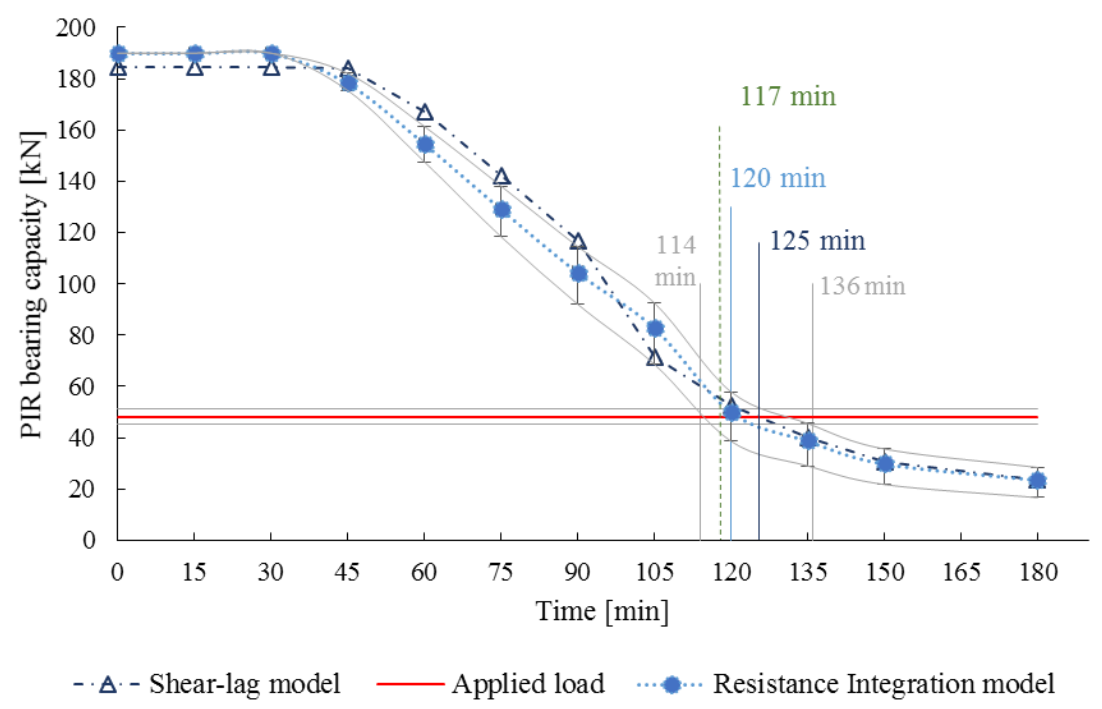

Fig. 16: Anchor fire resistance evolution calculated by Shear-lag and by resistance integration method

The fire resistance duration of chemical anchors is determined by the intersection between the anchor load bearing capacity evolution curve and the applied load curve. The Fig. 16 shows that the fire resistance duration predicted by the shear-lag model is 125 minutes $( \pm 5 \mathrm{~min})$ and the one predicted by the resistance integration method is 120 minutes $(+16 \mathrm{~min},-6 \mathrm{~min})$. However, the fire resistance duration measured experimentally is 117 minutes, which is close to those predicted by the two methods.

These results confirm the efficiency of the non-linear shear-lag model, presented in this paper, in determining the stress distribution along the anchor and in predicting the fire resistance duration of chemical anchors.

\section{Conclusion}

This paper presents a non-linear shear-lag model adapted to the mechanical problem of chemical anchors. The model allows the description of the axial and bond stress profiles, as well as the slip profile along the anchor for any temperature distribution. This model also allows the prediction of the moment of the initiation of the bond damage, leading to a decay in the anchor mechanical properties. The paper proposes a new solution to calculate automatically the length of the damaged portion of the bond, by solving the shear-lag differential equation in imposed displacement mode. The paper shows also that the stress distribution can be determined analytically when the temperature is uniformly distributed along the anchor by using simple cohesive laws. However, in case of a non-uniform temperature distribution, the resolution requires the use of numerical methods.

The shear-lag model showed that the stress distribution along the anchor depends on the temperature profile. Indeed, when temperature increases uniformly along the anchor, the axial stress profile becomes linear and the bond stress becomes uniformly distributed over the anchor elements. However, in case of a thermal gradient, the axial stress profile follows a logarithmic trend and the bond stress concentrates in the coldest zones of the anchor.

The comparison of the fire resistance duration predicted by the shear-lag model with that measured experimentally and that predicted by the resistance integration method presented in [33] shows that the shear-lag model correctly predicts the fire resistance of chemical anchors. In addition, the shear-lag model shows that when the anchor reaches its maximum axial force, all the elements composing the anchor provide their maximum performance at the same moment. This observation confirms and validates the assumptions on which is based the determination of the fire resistance duration of chemical anchors using the resistances integration method. 
In conclusion, the shear-lag model presented in this paper highlight the influence of the temperature variation on the mechanical behavior of chemical anchors and allowed to explain the ruin propagation. Moreover, in comparison with the resistance integration method results, the shear-lag model shows that taking into account the displacements compatibility between the anchor elements does not change much the predicted value load bearing capacity of the anchor for the geometry and mortar that was considered in this paper.

Nevertheless, several developments can be made on the shear-lag model presented in this paper in order to improve its accuracy. Indeed, the model considers the steel rebars as smooth rods and does not take into account the effect of the ribs, nor the non-axiality of the rebar. In addition, the model does not take into account the non-negligible effects of the thermal expansion, which can modify the stress profile. Moreover, the model does not take into account the thermal history of the resin nor its long-term behavior (creep), which can induce important modifications on the stress profiles and in the fire resistance duration.

Finally, the non-linear shear-lag model presented in this paper can be used to study the stress distribution along bonded anchors by offering the possibility to test new materials other than steel and concrete, such as the replacement of steel rebars by CFRP or GFRP, or the replacement of the concrete by solid wood or glued laminated timber.

\section{$\underline{\text { References }}$}

[1] F. Hugenchmidt, «New experiences with epoxies for structural applications», International Journal of Adhesion and Adhesives, vol. 2(2), pp. 84-95, April 1982.

[2] S. Chataigner, J.-F. Caron, A. Diaz Diaz, C. Aubergnac et K. Benzarti, «Non-linear failure criteria for a double lap bonded joint», International Journal of Adhesion and Adhesives, vol. 30, pp. 1020, 2010.

[3] V. A. Nguyen Trung, R. Le Roy et J.-F. Caron, «Multi-reinforcement of timber beams with composite materials: Experiments and fracture modeling», Composite Structures, vol. 123, pp. 233-245, 2015.

[4] S. Kumar, "Analysis of tabular adhesive joints with a functionnally modulus graded bondline subjected to axial loads», International Journal of Adhesion and Adhesives, vol. 29, pp. 785-795, 2009.

[5] S. Kumar et M. Khan, «A shear-lag model for functionally graded adhesive anchors», International Journal of Adhesion and Adhesives, vol. 68, pp. 317-325, 2016.

[6] O. Volkersen, «Die Niektraftverteilung in Zugbeanspruchten mit Konstanten Laschenquerschritten», Luftfahrtforschung, vol. 15, pp. 41-47, 1938.

[7] M. Goland et E. Reissner, «The Stresses in Cement Joints», Journal of Applied Mechanics, vol. 11, pp. A17-A27, 1944.

[8] D. Oplinger, «A layered Beam Theory for Single Lap Joints», Army materials Technology Laboratory Report, pp. MTL TR91-23, 1991.

[9] L. Hart-Smith, «Adhesive-Bonded single Lap Joints», NASA-Langley Contract Report NASACR-112236, 1973. 
[10] M. Tsai, D. Oplinger et J. Morton, «Improved Theoretical Solutions for Adhesive Lap joints», international journal of solids and structures, vol. 35(13), pp. 1163-1185, 1998.

[11] G. Wooley et D. Carver, «Stress Concentration Factors for Bonded Lap Joints», Journal of Aircraft, vol. 8, pp. 817-820, 1971.

[12] R. Carreira, J.-F. Caron et A. Diaz Diaz, «Model of multilayered materials for interface stresses estimation and validation by finite element calculations», Mechanics of materials, vol. 34, pp. 217-230, 2002.

[13] R. Alvarez-Lima, A. Diaz Diaz, J.-F. Caron et S. Chataigner, «Enhanced layerwise model for laminates with imperfect interfaces-Part 1: Equations and theoretical validation», Composite structures , vol. 94, pp. 1694-1702, 2012.

[14] A. Deb, I. Malvade, P. Biswas et J. Schroeder, «An Experimental and Analytical Study of the Mechanical Behavior of Adhesively Bonded Joints for Variable Extension Rates and Temperatures», International Journal of Adhesion and Adhesives, vol. 28, pp. 1-15, 2007.

[15] A. Pickett et L. Hollaway, «The analysis of elastic-plastic adhesive stress in bonded lap joints in FRP structures», Journal of Composite structures, vol. 4, pp. 135-160, 1985.

[16] A. Diaz Diaz, J.-F. Caron et R. P. Carriera, «Software application for evaluating interfacial stresses in inelastic symmetrical laminates with free edges», Composite structures, vol. 58, pp. 195-208, 2002.

[17] A. Diaz Diaz, J.-F. Caron et A. Ehrlancher, «Analytical determination of the modes I, II and III energy release rates in a delaminated laminate and validation of a delamination criterion», Composite structures, vol. 78, pp. 424-432, 2007.

[18] A. Diaz, R. Hadj-Ahmed, G. Foret et A. Ehrlacher, «Stress analysis in a classical double lap, adhesively bonded joint with a layerwise model», International journal of adhesion and ahdesives, vol. 29 , pp. 67-76, 2009.

[19] Y. Zhu et K. Kedward, «Methods of Analysis and Failure Predictions for Adhesively Bonded Joints of Uniform and Variable Bondline Thickness», U.S Departement of Transportation Federal Aviation Administration, Santa Barbara , may 2005.

[20] R. Hadj-Ahmed, G. Forêt et A. Ehrlacher, «Stress analysis in adhesive joints with a multiparticle model of multilayered materials (M4)», International journal of adhesion and adhesives , vol. 21, pp. 297-307, 2001.

[21] P. Das Neves, L. Da Silva et R. Adams, «Analysis of mixed adhesive bonded joints part II: Parametric study», Journal of Adhesion Science and Technology, vol. 23, pp. 35-63, 2009.

[22] I. Pires, L. Quintino, J. Durodola et A. Beevers, «A performance of a bi-adhesive bonded aluminium lap joints», International journal of Adhesion and Adhesives, vol. 23, pp. 215-223, 2003.

[23] B. Bouiadjra, H. Fekirini, B. Belhouari et B. Serier, «Fracture energy for repaired cracks with bonded composite patch having two adhesive bands in aircraft structures», Journal of Computational Material Science, vol. 40, pp. 20-26, 2007. 
[24] R. Carbas, L. Da Silva et G. Critchlow, «Adhesively bonded functionnally graded joints by induction heating», International Journal of Adhesion and Adhesives, vol. 48, pp. 110-118, 2014.

[25] CEN, «EN 1992-1-2 Eurocode 2. Part 1-2: Design of concrete structures - General rules Structural fire design», Bruxelles, Belgique; 2005.

[26] N. Pinoteau, «Behavior of Post-installed Rebars for Concrete in a Fire Situation», University Lille I (France), 2013.

[27] S. Chataigner, «Design of an anchorage for a cable made in composite material», Engineering sciences [Physics]. Ecole des Ponts ParisTech, pp. English. <pastel-00004865>, 2008.

[28] M. A. Lahouar, J.-F. Caron, N. Pinoteau, G. Forêt et K. Benzarti, «Mechanical behavior of adhesive anchors under high temperature exposure: Experimental investigation», International journal of adhesion and adhesives, vol. 78, pp. 200-211, 2017.

[29] W. H. Press, S. A. Teukolsky, W. T. Vetterling et B. P. Flannery, Numerical Recipes in C: The art of scientific computing (ISBN 0-521-43108-5), Cambridge: Cambridge University Press, 1988-1992.

[30] J. Chin, A. Forster, J. Ocel, J. Hartmann, P. Fuchs et D. Hunston, «Thermoviscoelastic Analysis and Creep Testing of Ambient Temperature Cure Epoxies Used in Adhesive Anchor Applications», Journal of Materials in Civil Engineering, pp. 1039-1046, 2010.

[31] CEB-FIB, Model Code 2010, final draft, September 2011.

[32] N. Pinoteau, J. Heck, R. Avnel, P. Pimienta, T. Guillet et S. Remond, «Prediction of failure of a cantilever-wall connection using post-installed rebars under thermal loading», Engineering structures, vol. 56, pp. 1607-1619, 2013.

[33] EOTA, «EAD 330087-00-0601, Systems for post-installed rebar connections with mortar», EOTA14-33-0087-06.01, July 2015. 